Mitteilungen der Österreichischen Geographischen Gesellschaft,

153. Jg. (Jahresband), Wien 2011, S. 31-74

\title{
Tourismus - Treiber des Wandels oder Bewahrer ALPINER KULTUR UND LANDSChaft? ${ }^{1)}$
}

\author{
Marius MaYer, Felix Kraus und Hubert JoB, alle Würzburg* \\ mit 6 Abb. und 2 Tab. im Text
}

\section{INHALT}

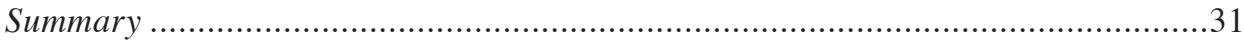

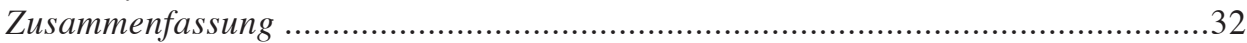

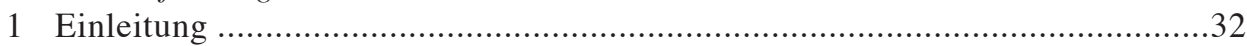

2 Theoretischer Hintergrund: Tourismus und Kultur(landschaft) .........................35

3 Stand der Forschung: Touristischer Einfluss auf die

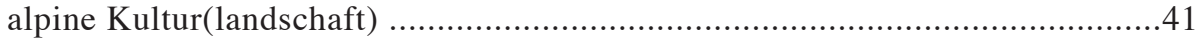

4 Wirkungen des Tourismus auf die Kulturlandschaft der Alpen.........................50

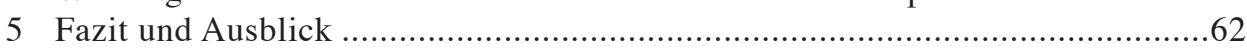

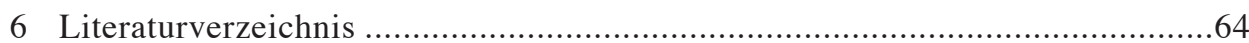

Summary

Tourism - driver of change or preserver of Alpine culture and landscape?

According to well-known critics tourism is often said to show negative cultural influences. Examples state that the customs of locals, the traditional way of life and the cultural landscapes are affected and commercialized. This critique has also been applied to tourism in the Alps - one of the most traditional destinations of global tourism. In a first step the most relevant conceptual and theoretical approaches aiming at explaining the relationship between tourism and culture/cultural landscapes are

\footnotetext{
1) Die Autoren danken Herrn em. o. Univ.-Prof. Dr. Dr. h.c. Karl Ruppert sowie zwei anonymen Gutachtern für die konstruktiv-kritischen Anmerkungen, Matthias Huttenlau, alpS GmbH, für die Aufbereitung des DTM sowie DI Dr. Michael Haupolter, Amt der Tiroler Landesregierung, Abteilung Umweltschutz und Mag. Johann Niedertscheider, Amt der Tiroler Landesregierung, Abteilung Raumordnung-Statistik für die freundliche Bereitstellung von Geodaten.

* Dipl.-Geogr. Marius MaYer, Dipl.-Wirtsch.-Geogr. Felix Kraus, o. Univ.-Prof. Dr. Hubert Job, alle Julius-Maximilians-Universität Würzburg, Institut für Geographie und Geologie, Lehrstuhl Geographie und Regionalforschung, Am Hubland, D-97074 Würzburg; E-Mail: vorname.name@uni-wuerzburg.de, http://www.human.geographie.uni-wuerzburg.de/personen/
} 
summarized by conducting a broad literature review. Second, the empirical results of existing research on the consequences of tourism for culture and landscape are compiled. Results demonstrate ambiguous cultural effects of Alpine tourism: On the one hand, traditional structures are preserved despite several processes of modernization, on the other hand they underlie a change process accelerated by tourism.

\section{Zusammenfassung}

Ein häufiger Topos der Tourismuskritik ist die zerstörende Wirkung des Tourismus in Bezug auf die Kultur der Einheimischen, die Vermarktung der selbigen, den traditionellen Lebensstil und die historisch gewachsene Kulturlandschaft. Diese Tourismuskritik bezieht sich auch auf die Alpen als eine der traditionsreichsten Destinationen weltweit. Eine umfassende Literaturanalyse resümiert zunächst die wesentlichen theoretischkonzeptionellen Erklärungsansätze der Wechselwirkungen zwischen Tourismus und Kultur(landschaft). Anschließend werden die Auswirkungen des Tourismus auf die alpine Kultur(landschaft) zusammengetragen. Die Resultate zeigen eine ambivalente Wirkung des Alpentourismus auf die Kultur(landschaft), deren tradierte Strukturen einerseits trotz vielfältiger Modernisierung sprozesse erhalten bleiben, aber andererseits einem durch den Tourismus beschleunigten Wandel unterliegen.

\section{Einleitung}

Die Alpen verkörpern eine reife Tourismusdestination. Viele traditionsreiche Tourismusregionen blicken dort auf eine 200-jährige Geschichte zurück. Die meisten Tourismusorte befinden sich heute mehrheitlich in der Stagnationsphase, in Teilen schon in der Niedergangs- bzw. Verjüngungsphase des Destinationslebenszyklus nach ButLer (1980). Nichtsdestotrotz überschreibt BätzING in seiner bekannten Alpenmonographie die Ausführungen zu unserem Thema mit: „Der Tourismus - keine Schlüsselbranche im Alpenraum“. Er reflektiert damit den empirischen Befund, dass etwa $40 \%$ aller Alpengemeinden nur eine marginale Tourismusintensität von unter 0,1 Betten je Einwohner aufweisen (Bätzing 2003, S. 157f.). Obgleich der Tourismus kein flächendeckendes Phänomen darstellt, existieren etliche alpine Regionen, in welchen der Tourismus als Leitökonomie räumlich und zeitlich konzentriert auftritt (vgl. Abb. 1) ${ }^{2}$. Entsprechend der naturräumlichen Gegebenheiten gilt dies beispielsweise

\footnotetext{
2) In den nach der Alpenkonvention abgegrenzten Alpen (TAPPEINER et al. 2008, S. 74ff.) gibt es in der zweiten Hälfte der 2000er Jahre etwa 240 Mio. direkt nachgewiesene Übernachtungen. Für die französischen Alpen liegt auf Gemeindeebene lediglich die Anzahl an Gästezimmern vor, aus denen sich die Gästebettenzahl und unter der restriktiven Annahme von 75 Übernachtungen pro Jahr eine ungefähre Größenordnung der dortigen Übernachtungszahl hochrechnen lässt. Damit erhöht sich die konservativ berechnete Gesamtsumme für die Alpen auf 330 Mio. Übernachtungen pro Jahr, wobei die Parahotellerie im italienischen Westalpenraum mangels verfügbarer Daten nicht adäquat abgebildet werden konnte,
} 
für alpine Seenbecken (z.B. Gardasee [Lago di Garda]) oder vom Wintersport stark geprägte Tourismusgebiete (z.B. Oberengadin).

Die Einflüsse des Tourismus auf die gastgebenden Gesellschaften, die Bereisten, die Kultur, Natur und Landschaft der Alpen werden seit vielen Jahrzehnten intensiv erforscht (vgl. Kap. 3). Der vorliegende Beitrag stellt den Versuch dar, eine Synthese dieser konzeptionellen wie empirischen Forschungsanstrengungen zu erstellen, um aus der Vielzahl von Einzelfallstudien allgemeine Tendenzen und Generalisierungen abzuleiten. In diesem Zusammenhang stehen Kultur und Kulturlandschaft als sich bedingende und miteinander vielfältig verwobene Phänomene im gemeinsamen Fokus der Untersuchungen - die meisten Arbeiten konzentrierten sich trotz dieser engen Zusammenhänge bisher nur auf eines der beiden Themen. Aufgrund dieses synthetisierenden Ansatzes besteht das methodische Vorgehen vorwiegend aus einer ausführlichen, schematisierenden Literaturanalyse (mit Schwerpunkt auf deutsch- und englischsprachigen Quellen - die französischen, italienischen und slowenischen Quellen zur Thematik konnten aus Zeit- und Platzgründen nicht eingesehen werden) zur überblicksartigen Erfassung der Auswirkungen des Tourismus auf die alpine Kultur(landschaft) (vgl. Kap. 3, Tab. 1). Bezüglich der Einzelaspekte der alpinen Kulturlandschaft stützt sich der Beitrag weitgehend auf eigene empirische Arbeiten.

Wichtig ist die Feststellung, dass weder originäre Kulturen noch kulturlandschaftliche Erscheinungsbilder alpenweit uniform sind (B̈̈тZING 2009, S. 298, 306). Kultur ist nicht nur in geographischer Hinsicht vielfältig, sondern unterliegt auch im zeitlichen Verlauf einem fortlaufenden Wandlungsprozess (THIEм 1994, S. 62). Für B ̈̈TZING (2009, S. 299) ist die Anerkennung dieser kulturellen Dynamik ausgesprochen wichtig, um sich von allen statischen und musealen Kultur-Vorstellungen abzusetzen. Kultur und kulturelle Werte werden nämlich oft als quasi-statische Entitäten gesehen, die vom Tourismus bedroht sind. So wird der Terminus ,Cultural Integrity “ im Kontext von internationalen Sustainable-Tourism-Debatten und gerade in Bezug zum Tourismus in Entwicklungsländern häufig verwendet (MundT 2011). Wenn sich eine dynamische Kultur stets wandelt, dann ,gibt es keinen ,Urzustand', der eine besonders ,klare', , echte' und, reine 'Form der Kultur repräsentiert, und der deshalb eine Norm darstellt, die man bewahren oder zu der man zurückkehren müsse“ (BäTZING 2009, S. 299). Thiem (2001, S. 28) führt die Ursprünge zum Teil massiver Kritik am Tourismus als kulturzerstörenden Faktor auf ein solches falsches, weil rein statisches Kulturverständnis zurück, das jedwede Veränderung des status quo per se ablehnt und die touristische Entwicklung als stärksten (exogenen) Einflussfaktor quasi als „Schuldigen“ sieht.

teilweise kleinere Destinationen $(<100.000$ Übernachtungen) nicht mit aufgeführt wurden, und allgemein auf den Trend zur Untererfassung speziell der nicht-gewerblichen Übernachtungen hingewiesen sei. Insgesamt erscheint somit die von SiEgRIST (1998, S. 426ff.) bestimmte Summe von etwa 370 Mio. Übernachtungen in den Alpen Mitte der 1990er Jahre eine nach wie vor gültige Größenordnung zu sein. Zum Tagesausflugstourismus in den Alpen gibt es keine alpenweiten, verlässlichen Größenordnungen. Zweifelsohne spielt er jedoch vor allem regional und lokal eine sehr bedeutende Rolle (z.B. in den oberbayerischen Alpen). 


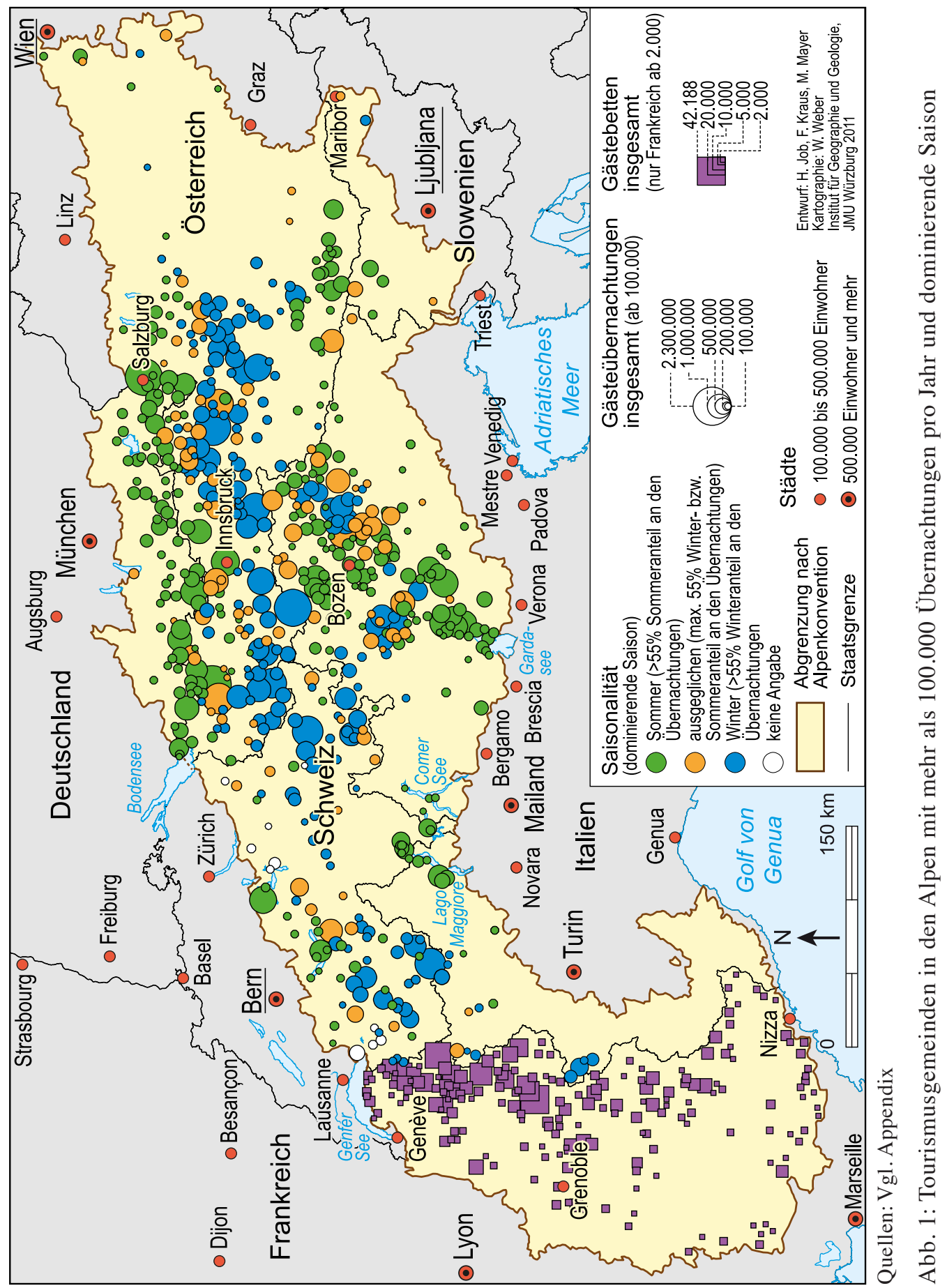


Angesichts vielfältiger Triebkräfte kultureller Wandlungsprozesse kann der Tourismus nicht monokausal als Haupt- oder gar alleiniger Verursacher des Kulturwandels betrachtet werden. Gerade die wissenschaftlich fundierte Kausalitätsbestimmung erweist sich nämlich in diesem Fall häufig als methodisches Hauptproblem vieler Studien (vgl. Kap. 2.1.1). Die heutige Globalisierung der Alltagskultur stellt ein weltweites Phänomen dar. Einerseits ist der Prozess dieser durch Massenmedien vorangetriebenen, beinahe ubiquitären gesellschaftlichen Modernisierung weit fortgeschritten (BARBER 2003); andererseits ist die touristische Erschließung der Alpen so gut wie abgeschlossen, manchmal gar eher rückläufig (u.a. in Teilen Oberbayerns [MAYER et al. 2008] oder in den italienischen Südwestalpen). Es kann demnach vermutet werden, dass heute gesamtgesellschaftliche Entwicklungen stärkeren kulturellen Einfluss ausüben als Reisende. Das gilt für Kulturen wie Kulturlandschaften der Alpen. ,Tirol City' und seine amorphe hochurbane Siedlungs- und Verkehrsinfrastruktur entlang des Inntals mit über 630.000 Einwohnern, einer Vielzahl von Berufspendlern und stetig wachsenden Teilnehmern am Transitverkehr (ANDEXLINGER et al. 2005, S. 21) sind ein Exempel dafür.

Die Ausübung des Tourismus ist vornehmlich landschaftsbezogen (z.B. Skifahren) und bewirkt somit unzweifelhaft eine Veränderung der alpinen Kulturlandschaft, die sich allerdings auch auf den Dauersiedlungsraum bezieht (Ortsbild, Architektur, Verkehrswege etc.). Dabei gilt es räumlich sowohl horizontal als auch vertikal zu differenzieren. Ebenfalls muss die Dimension der Zeit Berücksichtigung finden, da es sich beim Tourismus um ein ausgesprochen saisonales Phänomen handelt (BENDER et al. 2007).

Dieser Beitrag ist wie folgt aufgebaut: Zunächst werden die begrifflichen und theoretischen Grundlagen gelegt, wobei zentrale Konzeptionen der Einflüsse des Tourismus auf die Kultur(landschaft) vorgestellt werden. Kapitel 3 resümiert den Stand der Forschung in Sachen der schwer zu operationalisierenden Kultur(landschaft) in den Alpen, während anschließend anhand eines selbst erstellten Schemas die kulturlandschaftlichen Auswirkungen des Alpentourismus nach Höhenstufen und ausgewählten Problembereichen diskutiert werden. Abschließend werden Forschungsperspektiven aufgezeigt.

\section{Theoretischer Hintergrund: Tourismus und Kultur(landschaft)}

\subsection{Begriffliche Klärungen}

\subsubsection{Kultur}

Der Kultur-Begriff ist sehr vieldeutig und die Zahl einschlägiger Definitionsversuche Legion. Hier wird Kultur definiert als ein System von Konzepten, Wertvorstellungen, Normen und Einstellungen, das sowohl im Verhalten und Handeln der Menschen als auch in ihren geistigen und materiellen Produkten zum Ausdruck kommt. Vereinfacht gesagt ist Kultur die Art und Weise, wie Menschen leben und was sie aus sich selbst und ihrer Welt machen (Maletzke 1996, S. 15f.). Damit ist klar, dass nicht von einem 
Hochkulturverständnis (Тніем 1994, S. 29f.) ausgegangen werden sollte. Denn im Fall einer Beschränkung auf die Hochkultur würden sämtliche Bereiche der Alltagskultur und damit auch der Kulturlandschaft ausgeblendet, die als räumlich fassbare Resultate menschlichen Wirtschaftens zu verstehen sind. TERKENLI (2000, S. 185) bezeichnet deshalb Kulturlandschaften ,as the most tangible manifestations of culture in the geographical environment".

Es besteht ein weitgehender Konsens, dass der Tourismus in jedem Fall die Kultur beeinflusst, umstritten sind jedoch Stärke, Richtung und Kausalität, die kaum objektivierbar und von einer Vielfalt interner und externer Prozesse abhängig sind, vor allem im Hinblick auf andere Treiber kulturellen Wandels. Die jeweiligen Ergebnisse und Schlüsse über die Rolle und Wichtigkeit solcher Veränderungen sind dabei gesellschaftsspezifisch zu bewerten und abhängig von den jeweiligen Rahmenbedingungen (Kariel \& Kariel 1982, S. 1; TsChurtschenthaler 1986, S. 23; B ACHLEITNER \& Penz 2000, S. 73). Ein Hauptgrund für die mangelnde Zurechenbarkeit touristischer Einflüsse auf die Kultur der Zielregionen ist MörTh (2004, S. 8) zu Folge die Globalisierung, die zu Assimilationsprozessen und damit einer massiven Durchdringung der Kulturen untereinander und zur Bildung von Mischformen führt. Auslöser dieser Tendenzen sind unter anderem Migrationsprozesse, technologische Entwicklungen, die Konsumkultur und die Unterhaltungs- und Freizeitindustrie. Von Tourismus als „dynamic force homogenizing societies and comodifying cultures across the globe“ (REID 2003, S. 1) auszugehen, erscheint also stark übertrieben.

\subsubsection{Kulturlandschaft}

Was meint Kulturlandschaft in Relation zur Kultur? Klar sollte sein, dass in der Regel die Alltagskultur prägend ist für das Aussehen von Kulturlandschaft. Kulturlandschaftsforschung verlangt in diesem Kontext eine ganzheitlich-integrative wissenschaftliche Betrachtungsweise. Denn die von der Kulturlandschaft ausgehenden, faktischen Raumfunktionen sind vielfältig. Aber auch die Bedeutungsvielfalt ist umfänglich und reicht bezüglich unserer Themenstellung vom idealisierenden Stereotyp der klassischen Alpenromantik über die bloße Kulisse für hochtechnisierte Sportarten bis hin zur unter Rentabilitätsgesichtspunkten bewirtschafteten agrarischen Produktionsfläche.

Unter Kulturlandschaftsentwicklung versteht JäGER (1987, S. 28) „eine chronologische Ab-und Aufeinanderfolge von Formen, Gefügen und Funktionen, die sich durch Addition neuer Elemente oder durch den Übergang in einen anderen Zustand ergibt." Die Intensität der anthropogenen Überformung bestimmt dabei nicht nur die Ausprägung einzelner Formenkreise, sondern auch die Gesamtkonfiguration der Kulturlandschaft, die naturnähere oder naturfernere Züge anzunehmen im Stande ist (Јов 1999, S. 25).

Kulturlandschaft verändert ihr Erscheinungsbild, wie das gesamte kulturelle Erbe, getrieben durch den gesellschaftlichen Wandel, die Raumwirksamkeit unternehmerischer Entscheidungen und der politischen Rahmensetzungen sowie durch Veränderungen des naturgeographischen Potenzials (Bовек 1957). Dem gesellschaftlichen Wandel auf dem Fuße folgt der Wandel von Landschaft als Wahrnehmungskategorie. Das heißt, es geht auch um eine kulturell determinierte Realitätskonstruktion, um den Faktor der Ordnung des den Menschen umgebenden Raumes - zweifelsohne basiert eine solche aber auf historisch gewachsenen Konventionen (ICKERODT 2007). 
Zukunft ist zwar nicht planbar, aber doch gestaltbar. Somit gilt es für Raumwissenschafter darüber zu räsonieren, mit welcher Kulturlandschaft wir leben wollen und welche Rolle der Tourismus darin spielt. Demnach bleibt festzuhalten: Kulturlandschaft ist primär aus menschlichen Bedürfnissen und erst sekundär aus den Geofaktoren, die das Naturpotenzial darstellen, zu verstehen (RUPPERT 1976). Und Kulturlandschaften umfassen nicht nur - jeweils subjektiv zu wertende - schöne Landschaften, gewöhnliche und reizlose gehören ebenfalls dazu. Nach Differenzerfahrung suchend, meiden Touristen Letztere, obwohl in Teilen selbst dazu beitragend, im Urlaub (BundESAMT FÜR BAuwesen und RAUMORDNung 2001).

\subsection{Tourismus und Kultur - Konzeptionen}

\subsection{1 Überblick}

Es gibt verschiedene theoretisch-konzeptionelle Ansätze, die versuchen den Einfluss des Tourismus auf die Kultur zu erklären. Darunter wären das Drei/Vier/SechsKulturen-Modell, die Sichtweise touristischer Dienstleistungen als Theater-Metapher im Sinne Goffmans, die Akkulturationstheorie, das S-Kurven-Konzept der räumlichen Diffusion, sowie das ButLer'sche Phasenmodell des Destinationslebenszyklus (Tourist Area Life Cicle, TALC), anhand dessen die kulturellen Auswirkungen parallel zur allgemeinen Tourismusentwicklung an Relevanz gewinnen. Der durch den Tourismus induzierte kulturelle Wandel wird bereits seit längerem durch das Phänomen der Akkulturation, sowie den häufig verwendeten Begriff des Demonstrationseffekts erklärt, wie beispielsweise in Brougham \& ButLer (1981) und CoHen (1984). Als Akkulturation wird die exogen bedingte Auslösung des Kulturwandelprozesses durch die Übertragung ursprünglich fremder Kulturelemente und deren Integration in die eigene Kultur bezeichnet (REDFIELD et al. 1936, S. 149ff.; ausführlich LÜEM 1985, S. 48ff.).

Das S-Kurven-Konzept und der TALC weisen gewisse Gemeinsamkeiten auf: Während der Destinationslebenszyklus auf die quantitative Tourismusentwicklung fokussiert, konzentriert sich KARIELs Darstellung (1982, S. 2) auf den Übergang von ländlich-agrarischen hin zu urban-technisierten Gesellschaften, in dessen Rahmen mit zunehmendem Tourismus verschiedene soziale und kulturelle Veränderungen vonstattengehen. Gemäß dem Modell des Destinationslebenszyklus korrespondieren soziokulturelle Auswirkungen mit dem Tourismusaufkommen, das von Niveau und Dynamik touristischer Erschließung abhängt, die wiederum einzelnen Entwicklungsphasen und Wachstumsmustern unterliegt, was mit einer Veränderung der Gästestruktur einhergeht (Schimany 1997, S. 178ff.). Diese Argumentation steht in engem Zusammenhang mit der These von Sмiтн (1977, S. 8ff.), wonach der Einfluss des Tourismus auf eine Kultur und die Anpassungsbereitschaft der Gäste wesentlich von der Zahl der Besucher abhängen. Der Tourismus hat also nicht in jedem Raum die gleichen Auswirkungen: Es kommt auf die Vorprägungen an, auf die Entwicklungsdauer und -geschichte des Tourismus sowie die Zeit des Einsetzens der Tourismusentwicklung (BACHLEITNER \& Penz 2000). Die drei erstgenannten Konzepte weisen besonderen Erklärungsgehalt auf und werden daher in Abbildung 2 dargestellt: 


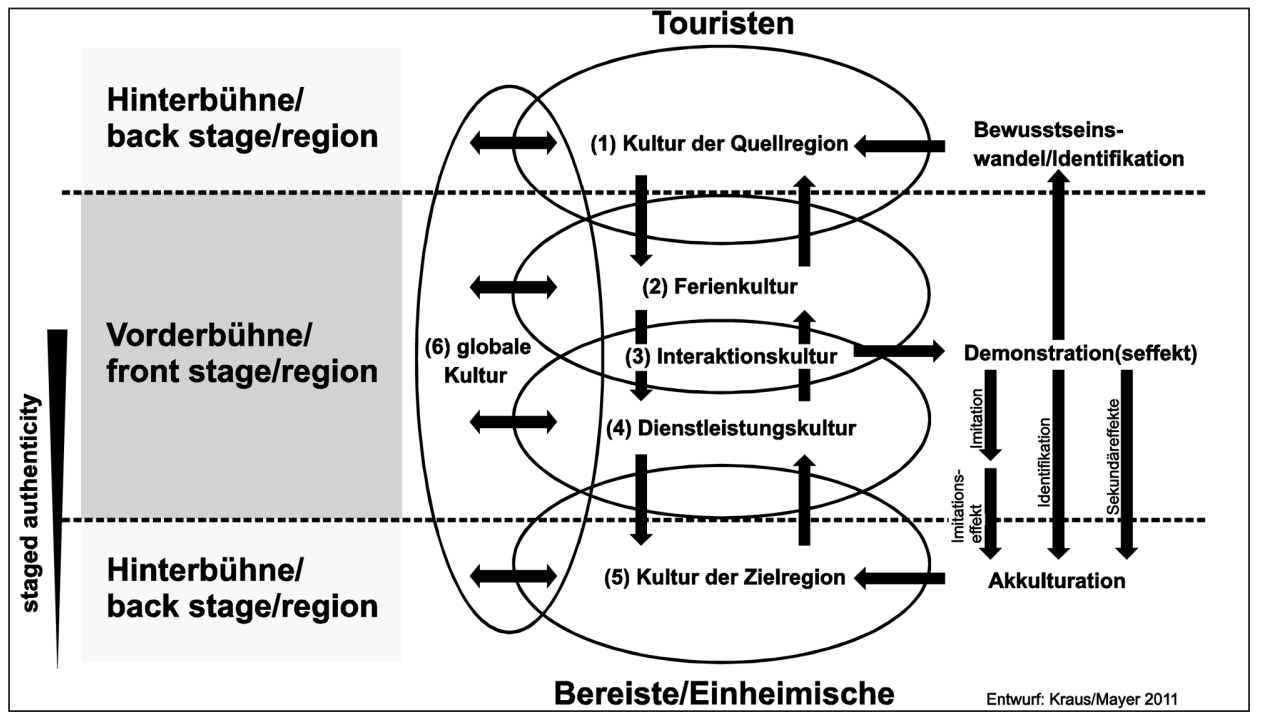

Quellen: Eigene Darstellung nach Thiem 1994, Schimany 1997, Goffman 1983, LüEm 1985, MÖRTH 2004

Abb. 2: Konzeptionelle Erklärungsansätze zum Verhältnis zwischen Tourismus und Kultur der Zielregion

\subsubsection{Das Vier-/Sechs-Kulturen-Modell}

Im Kern der Überlegungen zu den Auswirkungen des Tourismus auf Kulturen steht das von ThIEм 1994 in Erweiterung eines Ansatzes von JAFARI 1982 entworfene VierKulturen-Modell, das SCHIMANy 1997 zu einem Sechs-Kulturen-Modell transformierte. Das Modell geht von der Interaktion zwischen der (1) Kultur der Quellregion (aus der die Reisenden kommen, zumeist aus urbanisierten Räumen), der (2) Ferienkultur (dem Lebensstil, den Touristen auf Reisen praktizieren), der (4) Dienstleistungskultur (dem Lebensstil der Einheimischen in ihrer Rolle als Gastgeber) und der (5) Kultur der Zielregion (die ursprüngliche Kultur der bereisten Gebiete) aus. Zwischen diesen Kulturen gibt es jeweils Schnittmengen, etwa zwischen Ferienkultur und Dienstleistungskultur, wo der direkte Kontakt zwischen Touristen und ihren Gastgebern stattfindet. SCHIMANY (1997, S. 174) bezeichnet diesen Bereich als eigenständige (3) Interaktionskultur. Die dort anzusiedelnden Wechselwirkungen zwischen Ferien- und Dienstleistungskultur bilden denjenigen Bereich, in dem sich der Kulturkontakt und -austausch zwischen Reisenden und Bereisten primär vollzieht. Schließlich werden noch die Einflüsse - vor allem medial vermittelter - globaler Kultur (6) berücksichtigt, die andere Kulturen (partiell) überlagert. Die Interaktionen zwischen den verschiedenen Kulturen tragen zu Veränderungen in allen sechs Kulturen bei, bringen Teile eines urbanen Lebensstils aufs Land, führen zu neuen Berufen in der Dienstleistungskultur etc. Die Interaktionen können aus der Sicht der Bereisten sowohl positiv als auch negativ bewertet werden (Thiem 1994, S. 40ff.; Luger 1995, S. 33; Schimany 1997, S. 174). 


\subsubsection{Konzeption der Vorder- und Hinter-Bühne nach GoFFMAN}

Die zweite Konzeption zur Beschreibung der Beziehung zwischen Gastgebern und Gästen beruht auf GofFmans (1983 [1959]) Theater-Metaphorik einer Lebensbühne, auf der ,wir alle“ im Alltag Theater spielen. Das heißt, die alltägliche Selbstdarstellung erfolgt wie auf einer Bühne, die in eine „Vorderbühne“ und eine „Hinterbühne“ einzuteilen sei. Auf den Tourismus übertragen wurde diese Metapher erstmals von MacCannell $(1973,1976)$. Im Tourismus wird die Vorderbühne, wo die Begegnung zwischen Touristen und Einheimischen erfolgt, als Inszenierung der einheimischen Darsteller verstanden, in der die Einheimischen dem Touristen-,„Publikum“ die herzlichen Gastgeber vorspielen, aber auch die Touristen die Rollen ihrer jeweiligen Ferienkultur verkörpern. Die Vorderbühne entspricht dem Kontinuum aus Dienstleistungs-, Interaktions- und Ferienkultur im Sechs-Kulturen-Modell und muss wenig bis nichts mit der Kultur der Zielregion gemeinsam haben.

Ihre wahre Identität geben die Einheimischen nur auf der Hinterbühne preis. Diese Hinterbühne bietet den räumlich wie zeitlich fassbaren Zufluchtspunkt (Nebensaison), in der man sein normales Leben, einen Alltag ohne Touristen, weiterleben kann. Deshalb grenzen die Akteure die Hinterbühne vom Publikum ab, um einerseits ihren persönlichen Freiraum zu sichern und andererseits die Perfektion touristischer Inszenierung nicht zu stören. Durch die ständige Präsenz der Touristen in vielen Destinationen wurde die Hinterbühne nicht nur kleiner, sondern - so die Hypothese - immer stärker von der Vorderbühne geprägt, die Kultur der Zielregion mit Elementen der Dienstleistungskultur versetzt und von dieser zusehends durchdrungen (MACCANNELL 1973, S. 590ff.; Luger 1995, S. 32; Luger \& Rest 2002, S. 27; Mörth 2004, S. 13ff., 22ff.).

Die nach MacCannell (1973, S. 589f.) der modernen Gesellschaft inhärente Suche nach authentischen Erfahrungen macht es für die Touristen zunehmend interessant, auf der Suche nach dem vermeintlichen „Echten“ einen Blick hinter die Kulisse der Vorderbühne zu werfen, um das „wahre“ Leben, d.h. die Hinterbühne zu Gesicht zu bekommen. Dafür sind Touristen auch bereit, eine „,authentische“ Reproduktion zu akzeptieren, wobei eine für die Touristen vermeintlich ursprüngliche Hinterbühne dargeboten wird, die aber lediglich der als solcher inszenierten Vorderbühne entspricht (staged authenticity im Sinne MacCannells). Erwartet wird die Kultur der Zielregion, präsentiert wird jedoch die Dienstleistungskultur (DwORSCHAK 1994, S. 27; Schimany 1997, S. 182f.; Herdin \& Luger 2001, S. 14). Durch die Inszenierung der Vorderbühne als authentische Hinterbühne wird versucht, diesem Wunsch der Touristen nach Authentizität zu entsprechen, wobei unklar bleibt, ein wie großer Anteil der Gäste diese Inszenierung durchschaut und wenn ja, sich überhaupt daran stört. Die staged authenticity dient vor allem dazu, von Touristen erwarteten Stereotypen und Rollenklischees zu entsprechen. Die Inszenierung von Authentizität macht auch das vordergründige Paradoxon begreifbar, wie eine hochtechnisierte Infrastruktur mit dem Stereotyp des Ursprünglichen, Unverfälschtem zusammenpasst (z.B. Almhütten mit High-tech-Ausstattung hinter den Kulissen, ZEIT Magazin 2010). 


\subsection{Tourismus und Kulturlandschaft}

Die Auswirkungen des Tourismus auf die Kulturlandschaft sind in der Literatur vielfach dargestellt, bislang fehlt aber ein holistischer Theorie- und Analyserahmen (Terkenli 2004, S. 346). Die meisten Konzeptionen zum Thema Landschaft und Tourismus in den Alpen wurden in den 1980er Jahren veröffentlicht. LichtENBERGER (1979, S. 401ff.) stellt in einem bipolaren sozialökologischen Modell die Sukzession vom Agrar- zum Freizeitraum in den Hochgebirgen Europas dar. Da die ökologischen Potenziale und Ansprüche beider Nutzungsformen nicht deckungsgleich sind, kommt es räumlich gesehen nur zu einer partiellen Überlagerung, d.h. Integration (beispielsweise durch touristischen Nebenerwerb). In Räumen, wo die ökonomische Marginalität nicht durch eine Attraktivität für den Tourismus ausgeglichen wird, kann es zu Wüstungen kommen, in agrarischen Gunstlagen wird die Landwirtschaft modernisiert. KESSLER (1990, S. 378) kritisiert diese unaufhaltsam-zwangsläufigen Konsequenzen jedoch als zu pauschal. Lichtenberger beklagt die Vernachlässigung der dritten Dimension in bisherigen raumwissenschaftlichen Modellen und fügt die höhenabhängige, saisonale Verschiebung der Nutzungsschwerpunkte vom Agrar- zum Freizeitraum hinzu. Die Saisonalität des Alpentourismus ist also höhenstufenabhängig (LiCHTENBERGER 1979, S. 401ff.). KessLeR (1990, S. 380) schlägt darüber hinaus die Hangexposition und Eignung für den Skitourismus als vierte Dimension vor.

Der touristisch induzierte Landschaftswandel ist in den Alpen vielerorts deutlich sichtbar, obwohl viele Auswirkungen nicht unmittelbar zu beobachten sind und erst mit zeitlicher Verzögerung auftreten. Die Frage nach der Steuerbarkeit der Prozesse und das Verständnis für die komplexen Zusammenhänge im System Tourismus und Landschaft wird durch die „Tourismuswachstumsmaschine“ nach KRIPPENDORF (1987, S. 54ff.) vereinfacht dargestellt und erläutert. In dieser metaphorischen Darstellung wird die Vernetzung zwischen fünf verschiedenen sogenannten Kreiseln und deren Eigendynamik offenbar. Das komplexe Ineinandergreifen der Kreisel zwischen dem Wachstum der touristischen Nachfrage, der Einkommenswirkung, den Auswirkungen auf die Landwirtschaft und somit indirekt auf die Landschaft, den direkten Wirkungen auf die Landschaft und die Kultur zeigen die komplexen Wirkungszusammenhänge und veranschaulichen, welche Eigendynamik der Tourismusentwicklung innewohnt. Das System Tourismus-Berglandwirtschaft-Umwelt nach Messerli (1989, S. 114ff.) ähnelt KripPEndorfs Modell im Aufbau und in den Systemzusammenhängen, legt aber einen größeren Schwerpunkt auf die Veränderung des Wertsystems, mit der eine Abwertung der bergbäuerlichen Tätigkeit einhergeht.

Die genannten Analysekonzepte gehen im Allgemeinen von einer ungebremsten Tourismusentwicklung in den Alpen aus und beziehen noch keine späteren Phasen des Destinationslebenszyklus ein, die im Sommertourismus (am Beispiel Tirol) ungefähr ab 1972 und im Winter ab ca. 1982 einsetzen (Jов 2005, S. 123ff.). Die weitere Entwicklung des Alpentourismus mit den dazugehörigen Innovations- und Konsolidierungsprozessen sowie dem Niedergang mancher Destination wurde bisher noch nicht in eine Konzeption des Landschaftswandels eingebettet. 


\section{Stand der Forschung: Touristischer Einfluss auf die alpine Kultur(landschaft)}

Die soziokulturellen Auswirkungen des Alpentourismus können mit BätzING (2003, S. 168) als „Tabu-Thema“ bezeichnet werden, das vor allem von Verantwortlichen aus begreiflichen Gründen ungern angesprochen wird. Erschwerend hinzu kommt die Dominanz von Einzelfallstudien, die bis auf wenige Ausnahmen (z.B. WiLHELM 1977, 2001, Kariel \& Kariel 1982, Kariel 1989) Momentaufnahmen darstellen und somit keinen zeitlichen Längsschnittvergleich ermöglichen. Eine Übersicht der zugänglichen empirischen Studien (fast ausschließlich dem deutsch- und englischsprachigen Raum entstammend) zeigt, dass die Forschung über die kulturellen Folgen des Tourismus in den 1970er Jahren parallel zur größten touristischen Erschließungsphase der Alpengeschichte einsetzt und ihren Höhepunkt gleichzeitig mit dem Kulminationspunkt der Tourismuskritik ${ }^{3)}$ (z.B. KRIPPENDORF 1987) am voll etablierten alpinen Massentourismus in Sommer- und Wintersaison Mitte der 1980er bis Mitte der 1990er Jahre erreicht hat. Hierbei sind vor allem die Ergebnisse der MaB-Projekte in der Schweiz (z.B. MüLLER 1986) und Österreich (z.B. Preglau et al. 1985) zu nennen. In der ersten Dekade des neuen Jahrtausends sind nur noch wenige empirische Studien zur Thematik erschienen. Auf die möglichen Gründe für das offensichtliche Abflauen des Forschungsinteresses wird in Kapitel 5 eingegangen.

Der unmittelbare Zusammenhang zwischen Tourismus und Landschaft macht es notwendig, die Wahrnehmung und Bewertung der Landschaft durch unterschiedliche Akteursgruppen zu untersuchen. HunZIKER et al. (2007) geben einen fundierten Überblick über den Forschungsstand zum Thema „Landscape Preferences“. Studien, die über die Wahrnehmung des induzierten Landschaftswandels hinausgehen und explizit auf die Kulturlandschaftsentwicklung und den Tourismus abheben, sind weniger verbreitet als man angesichts der oft heftigen Kritik am „Landschaftsfresser“ (KRIPPENDORF 1975) Tourismus vermuten dürfte. Dabei werden die Auswirkungen des Tourismus auf den Kulturlandschaftswandel häufig nur am Rande und beispielhaft betrachtet. In den vergangenen Jahrzehnten haben dabei insbesondere die Auswirkungen des Agrarstrukturwandels im Fokus gestanden (Borsdorf \& Bender 2007, S. 29f.). In den Studien zu diesem Thema werden vor allem die Wechselwirkungen zwischen Landwirtschaft und Tourismus thematisiert und wird teilweise als sekundäre Aussage auf den Erhalt der Kulturlandschaft durch den Tourismus hingewiesen (z.B.: RUPPERT 1963, Penz 1978, Arnberger et al. 2006, Mayer et al. 2010). Weitere Phänomene wie das Flächenwachstum und die Strukturveränderung von Siedlungen sowie die Ausbreitung touristischer Infrastruktur werden häufig nur als direkte Effekte des Tourismus dargestellt, es werden aber selten fundierte Analysen und Inventarisierungen der Landschaft durchgeführt. Inventare kulturlandschaftlicher Touristifizierung sind somit rar und zumeist als Einzelfallstudien konzipiert (z.B. Kessler 1990, PINGOLD 2007, KeLLER 2007). Der damit verbundene Aspekt der Zweitwohnungen ist seit eini-

\footnotetext{
3) Nicht zufällig fällt der satirische, tourismuskritische Fernseh-Mehrteiler „Die Piefke-Saga“ (1990/93) nach dem Drehbuch des Tiroler Schriftstellers Felix Mitterer in denselben Zeitraum (DecKer 2001).
} 
gen Jahrzehnten Teil der Diskussion im Kontext von negativ bewerteter Zersiedelung, Flächeninanspruchnahme und uniformer Architektur (CIPRA 2008, S. 4).

Die Gestalt der touristischen Infrastruktur ist ein wesentlicher Teil der Kulturlandschaft. So sind Almen ein immer wiederkehrendes Vorbild für die gestalterischen Möglichleiten der Architektur (ConRAd 1994, S. 279f.). Doch bereits AchleItner (1986) konstatiert, dass bei der Betrachtung der häufig abwertend als „Lederhosenstil“" und „Jodlerburgen“ bezeichneten Beherbergungsarchitektur die wissenschaftliche Grundlage weitgehend fehlt. Somit ergibt sich die etwas paradoxe Situation, dass einem praktisch ubiquitär feststellbaren Phänomen, der baulichen Uniformisierung der Tourismusorte, bisher nur punktuelle und wenig systematische Untersuchungen gegenüberstehen. Die Thematik bleibt jedoch aktuell, wofür zum Beispiel die Gründung der Architekturzeitschrift „ARChALP“ des Institutes für Architektur in Berggebieten spricht oder die Diskussion um die höhere Besteuerung von Zweitwohnungen in Südtirol (Autonome Provinz Bozen-Südtirol 2009).

Flächeninanspruchnahme und Verbauung der Landschaft finden aber nicht nur in den Tallagen statt, wo die Treiber des Wandels vielfältig sind, sondern treten auch in den höheren Lagen auf, wo durch den Ausbau der touristischen Infrastruktur ein tiefgreifender Veränderungsprozess stattgefunden hat. Dieser erstreckt sich von der Errichtung komplett neuer touristischer Siedlungen (KNAFOU 1978) - die Höhengrenze der Siedlungstätigkeit wurde in touristisch erschlossenen Tälern somit stabilisiert oder sogar nach oben verschoben - über damit in Zusammenhang stehende Verkehrserschließung zu skitouristischen Aufstiegshilfen und damit verbundenen Baumaßnahmen von Skiabfahrten.

Die quantitative Entwicklung der touristischen Transporteinrichtungen wird in verschiedenen Untersuchungen dargestellt, wobei vorwiegend auf alpine Teilräume eingegangen wird und die Landschaftswirkung nur ein Teilaspekt ist (PHILIPP 1974, JÜLG 2001, DiETMANN et al. 2005) oder aufgrund der thematischen Fokussierung nicht dargestellt wird (Leitner 1984, Hannss \& SChröDer 1985, MAYer 2009). Die Liftanlagen stellen direkte Eingriffe in den Landschaftshaushalt dar. Darunter versteht man die infrastrukturellen und baulichen Maßnahmen zur Förderung und zum Erhalt des Winter- und Sommertourismus. Hierunter fallen auch der Hüttenbau sowie die Errichtung von Aussichtsplattformen und Klettersteigen. Diese direkten Eingriffe werden insbesondere in der Öffentlichkeit, aber seltener wissenschaftlich diskutiert, wie beispielsweise die Erbauung der Aussichtsplattform AlpspiX auf dem Osterfelderkopf bei Garmisch zeigt (DAV 2010). Die nicht neue Debatte dreht sich hierbei vor allem um die Eventisierung der Alpen, die Authentizität und die Erhaltung der Berglandschaft (ERLACHER 2008). Die indirekten Eingriffe werden durch die intensive Nutzung im Zusammenhang mit dem Freizeitverhalten der Touristen und die weitreichenden ökologischen Folgewirkungen verursacht. In diesem Themenbereich gibt es eine Vielzahl von Studien zu den geoökologischen Folgen durch die verschiedenen Belastungen, wie zum Beispiel Skifahren mitsamt der notwendigen Präparation und der Wegenutzung im Sommertourismus (GRABHERR 1987, RADEMACHER 2006). Im Zuge der Ausbreitung technischer Beschneiung wurden deren landschaftsökologische Folgen in Bezug auf Bau und Betrieb untersucht (RIXEN et al. 2003, PröBstL 2006). 
Im Folgenden werden die Auswirkungen des Tourismus auf die alpine Kultur(landschaft) nach den Dimensionen Kulturlandschaft und Kultur im weiteren Sinne aufgegliedert. Die Kulturlandschaft wird wiederum in die Teil-Bereiche Landwirtschaft, Infrastruktur und Bautätigkeit sowie Tourismus unterteilt, während die Kultur im weiteren Sinne in die individuelle Ebene (Reproduktion der personalen Identität), die gesellschaftliche Ebene (soziale Integration) und kulturelle Reproduktion differenziert wird. Diese letztgenannte Unterscheidung geht auf den Soziologen Preglau (1998, S. 59) zurück. Die Auswirkungen werden weiterhin gemäß der jeweiligen Konnotationen in den Quellen nach positiven, negativen und indifferenten Einflüssen gegliedert aufgrund der notwendigen Generalisierungen und der Heterogenität der einfließenden Studien sind mehrdeutige Einordnungen nicht überraschend (vgl. Tab. 1).

Zusammenfassend lässt sich aus Tabelle 1 eine deutliche Kongruenz der Ergebnisse verschiedener empirischer Studien ablesen. Die sich ergebenden Widersprüche lassen sich einerseits durch die Unterschiede in Forschungsdesign, Zeitperiode und Untersuchungsgebiet begründen und andererseits durch die generelle Ambivalenz des Tourismus in seinen soziokulturellen/kulturlandschaftlichen Auswirkungen (FindL-Ludescher 1994, S. 187). Ein Vergleich mit der außeralpinen Forschung zum Thema bestätigt die Ergebnisse von Tabelle 1 aufgrund großer Übereinstimmungen. Als negative Konsequenzen des Tourismus für die Kultur der Bereisten werden unter anderem die Ökonomisierung der Lebenswelten, Verlust von Traditionen, Brauchtum und Werten, Verlust von Authentizität, ökonomische Vermarktung von Traditionen und Bräuchen (commoditization), Verschlechterung des Gesellschaftslebens, soziale Spannungen und Konflikte, Veränderung von zwischenmenschlichen Beziehungen und Symptome wie z.B. Drogenabhängigkeit, physische und psychische Krankheiten und Kriminalität genannt. Als positive Effekte werden die Entstehung und Wiederbelebung kultureller Identität, sozialer Zusammengehörigkeit, von Traditionen, Bräuchen und Werten, sowie interkulturelle Kontakte und Lernprozesse im Sinne einer kulturellen Bereicherung beschrieben (UNESCo 1976, MANSPERgER 1995).

Von den Betroffenen in den untersuchten Alpenregionen werden die Effekte des Tourismus insgesamt überwiegend positiv bewertet (KARIEL \& Kariel 1982, S. 14; Högl 1995, S. 61ff.; Bachleitner \& Penz 2000, S. 107). Verschiedene Autoren warnen davor, die kulturverändernde Wirkung des Tourismus in den Alpen durch eine Gleichsetzung mit Ergebnissen aus Entwicklungsländern überzubetonen. Durch die grundsätzliche Verwandtschaft und Ähnlichkeit der Kulturen von Quell- und Zielregion sind die generellen Unterschiede und die Möglichkeit zur gegenseitigen Beeinflussung deutlich begrenzt. Zudem erfolgte kein Kulturschock, da sich die Akkulturation über Jahrzehnte erstreckte und auf Basis einer bereits etablierten Wirtschaftsstruktur erfolgte (Hanisch 1994, S. 110; B achleitner \& Penz 2000, S. 62).

Einige der in Tabelle 1 genannten soziokulturellen Probleme haben sich tendenziell abgemildert. Dies trifft auf die als besonders belastend empfundene Privatzimmervermietung mit ihrer ständigen, direkten Nähe von Gastgebern und Touristen zu. Durch den starken Rückgang dieser Beherbergungsform im Zuge einer allgemeinen Professionalisierung (EDER et al. 2005a,b), der Umwandlung in Ferienwohnungen mit weniger Kontakt bzw. der Schaffung von Rückzugsräumen für die Gastgeber - d.h. 


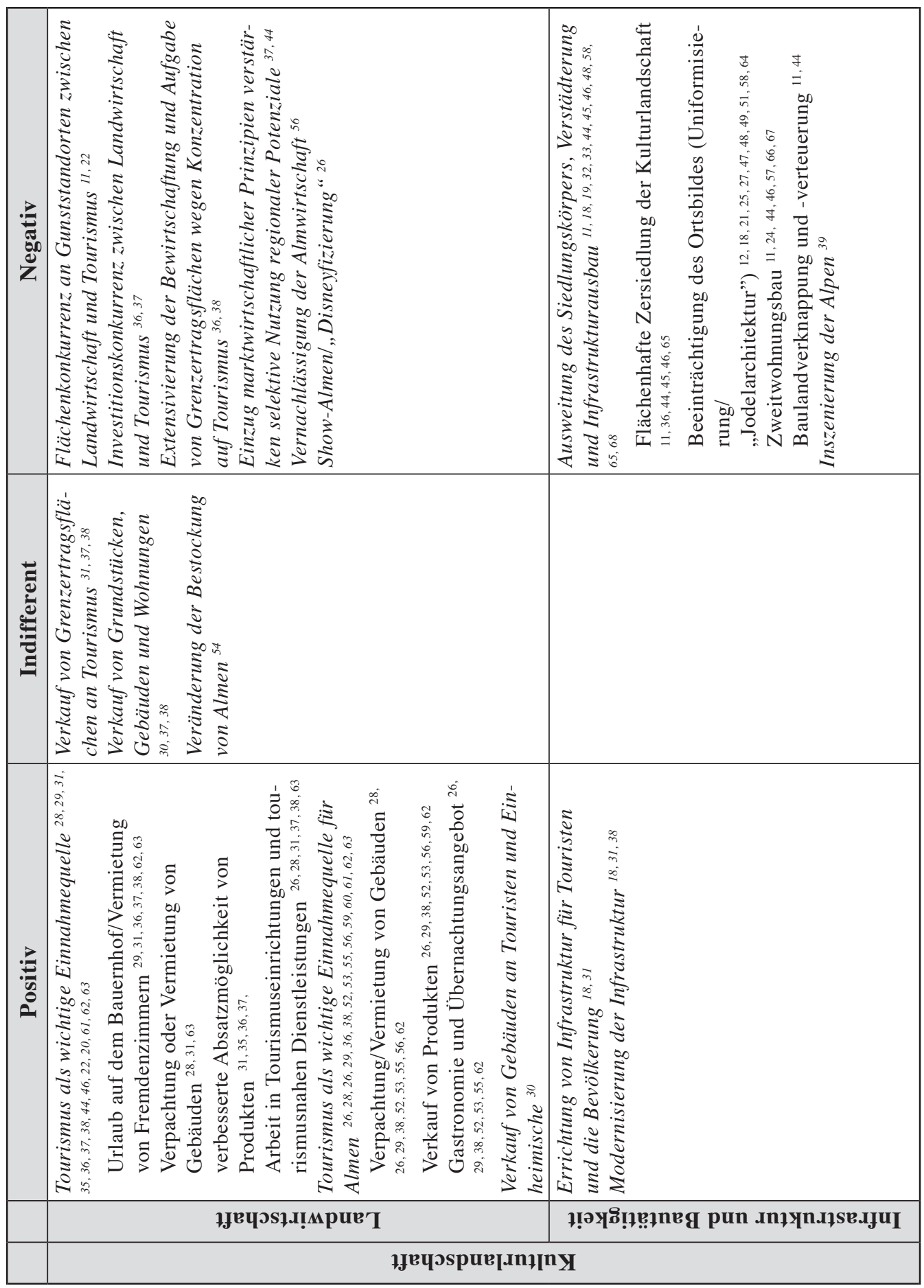




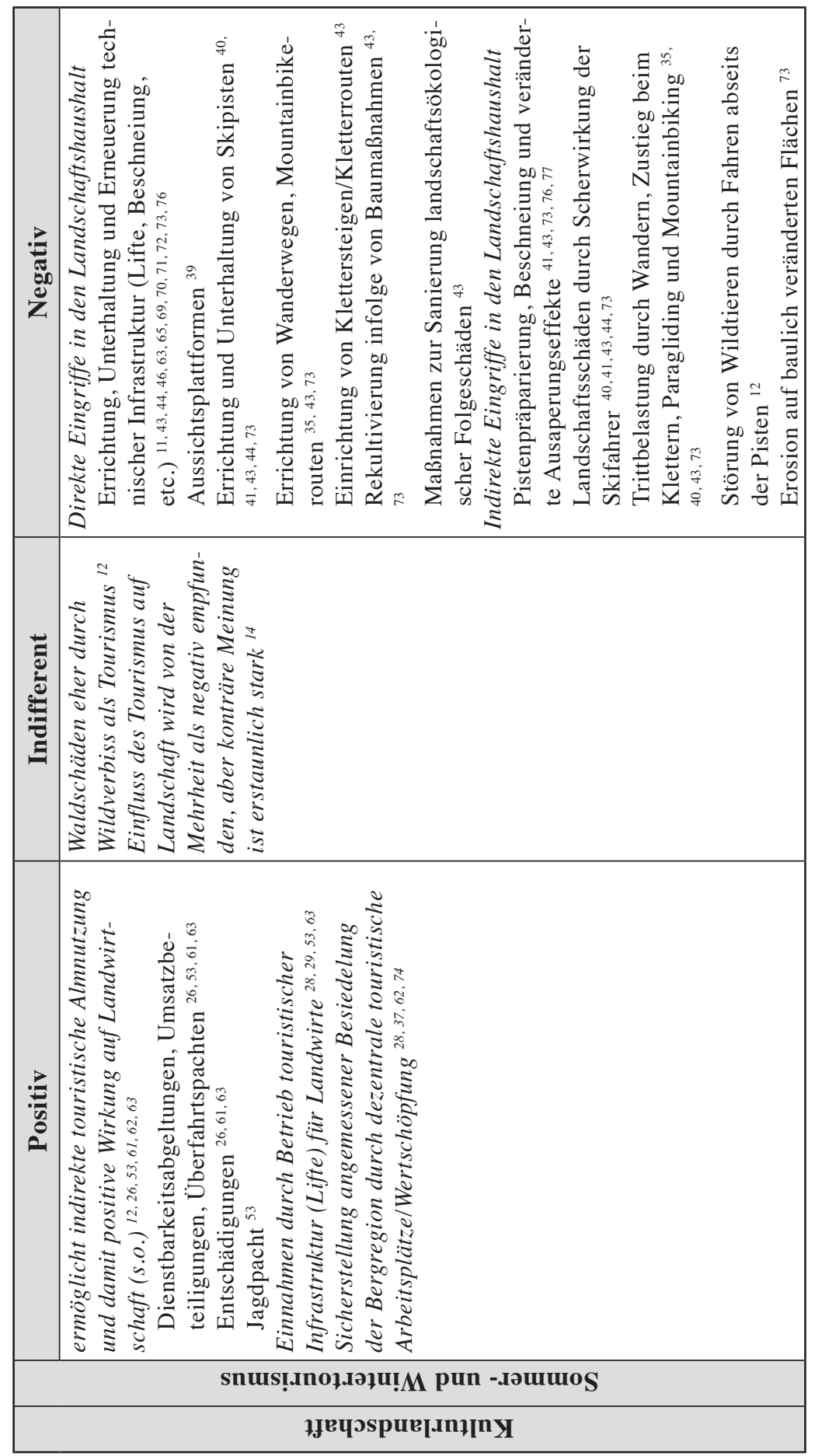




\begin{tabular}{|c|c|c|}
\hline & 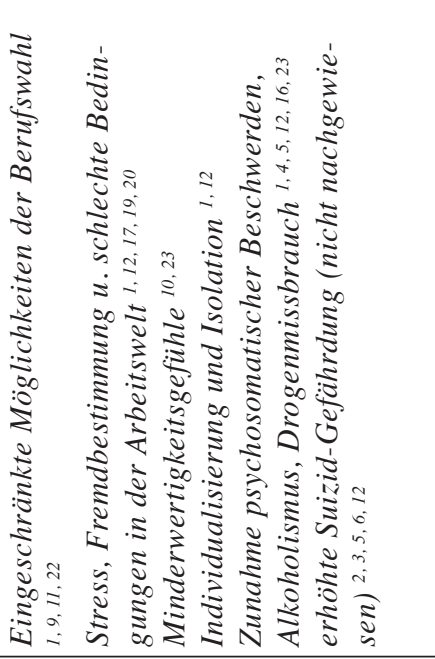 & 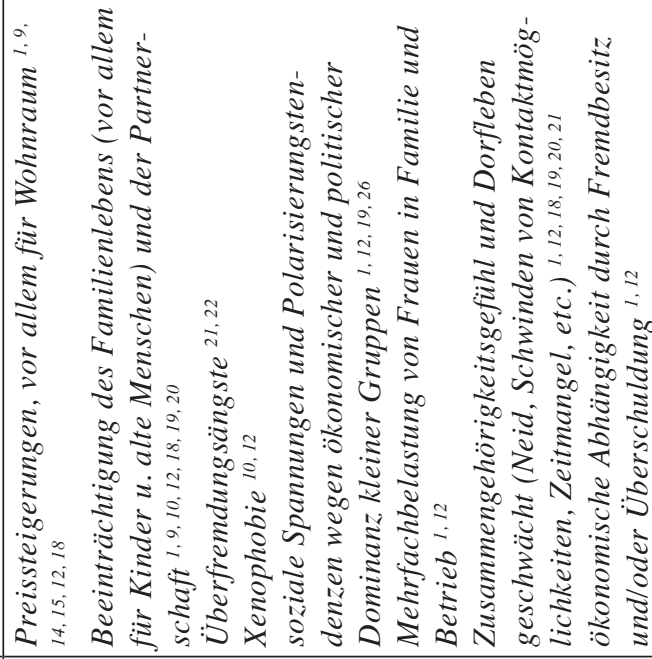 \\
\hline 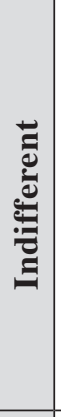 & 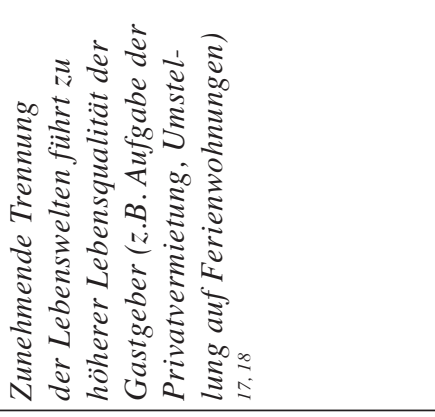 & 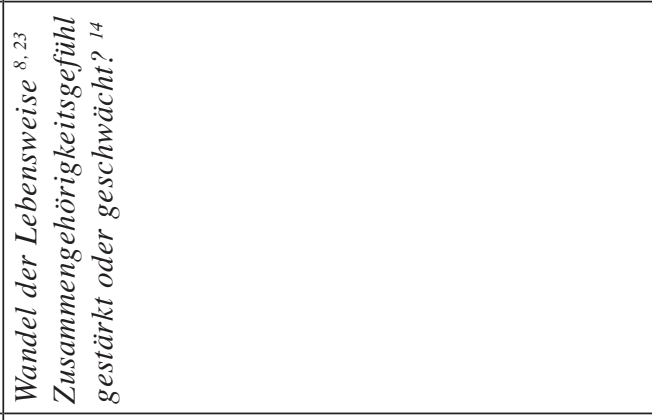 \\
\hline 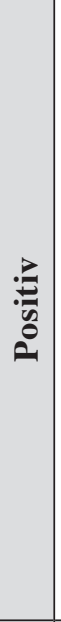 & 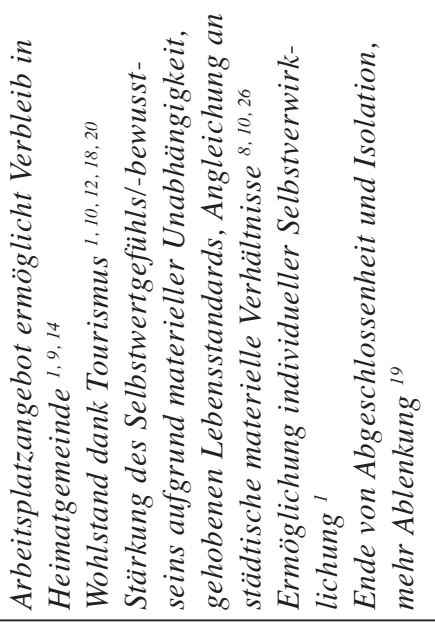 & 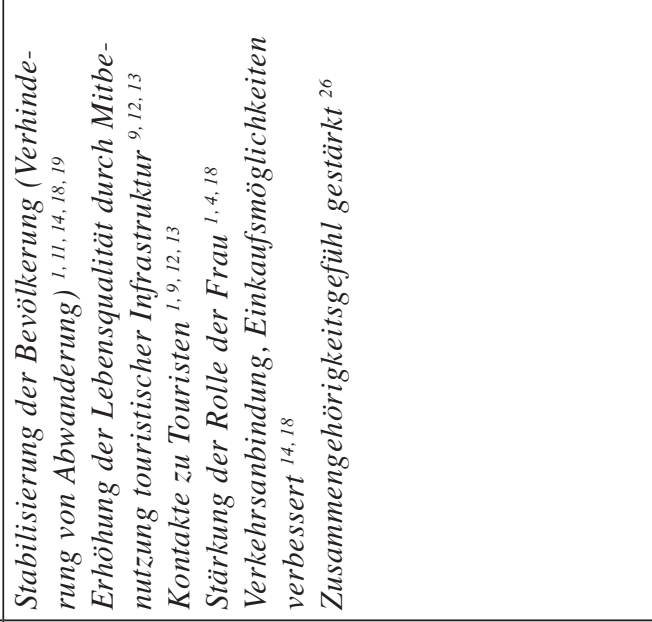 \\
\hline & 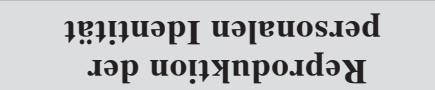 & 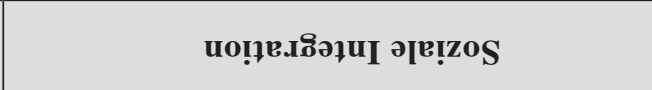 \\
\hline & \multicolumn{2}{|c|}{ 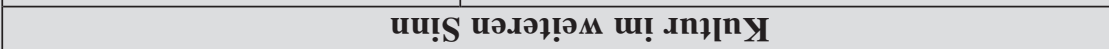 } \\
\hline
\end{tabular}




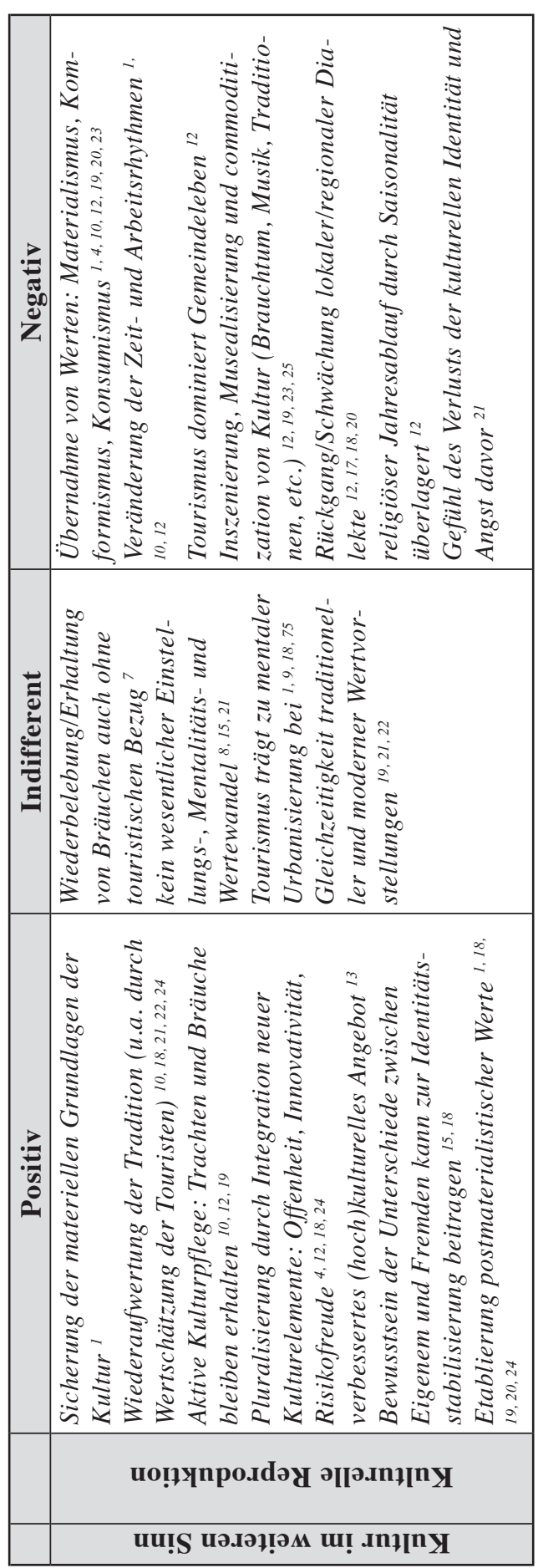

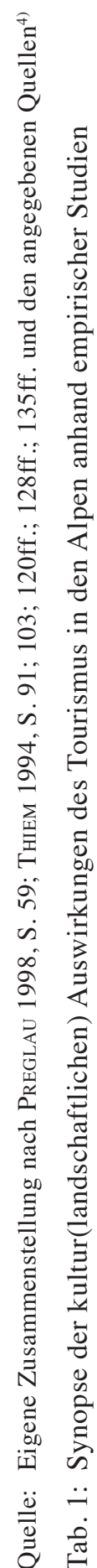

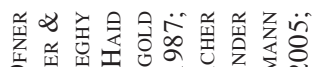

:

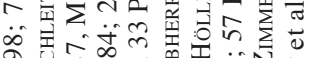

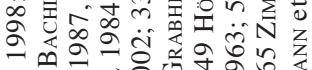

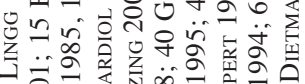

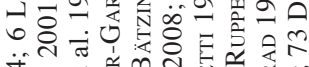

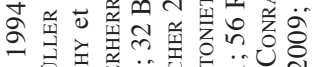

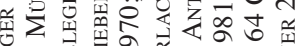

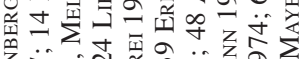

落的要

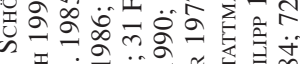

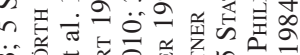

过

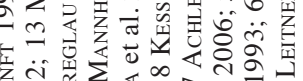

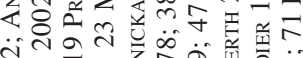

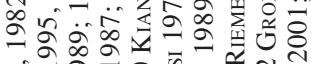

政

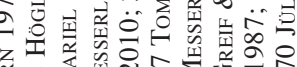

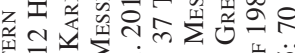

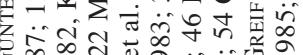

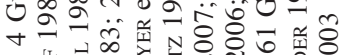

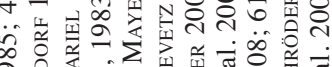

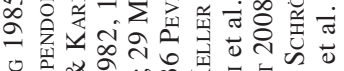

ơ $\nsim$

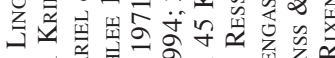

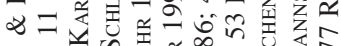

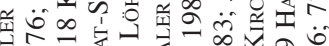

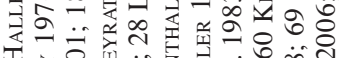

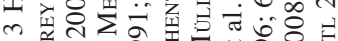

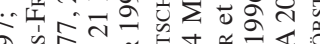

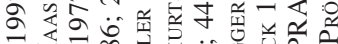

落

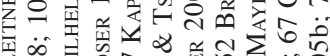

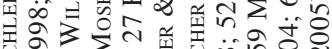

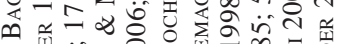

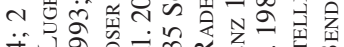

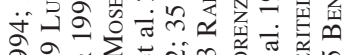

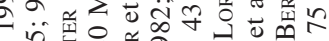

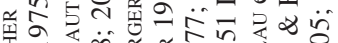

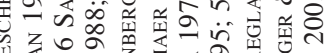

崫

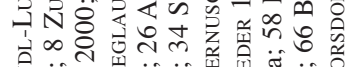

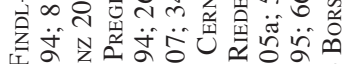

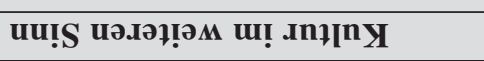

于 
einer klaren Trennung von front und back region - haben sich die negativen Einflüsse auf das Privatleben der Gastgeber vermindert (Högl 1995; WILHELM 2001, S. 144). So ist es möglich, dass selbst in stark touristisch genutzten Räumen noch vom Tourismus unabhängige Bräuche existieren oder wiederbelebt werden können, wie ÖFnER (1994) am Beispiel der Gurgler Gemat im Ötztal belegt.

Aus der Literatur lassen sich zwei Dimensionen ableiten, die den Umfang soziokultureller Probleme durch Tourismus in den Alpen maßgeblich determinieren: die zeitliche Dimension, d.h. die Dauer und Geschwindigkeit der touristischen Entwicklung sowie die raumzeitliche Intensität und davon abhängig die Konzentration der Wirtschaftsstruktur auf den Tourismus (Messerli 1987, S. 20). Daraus ergibt sich die bereits von GUNTERn $(1979,1982)$ formulierte Hypothese eines „cultural lag“: In einem solchen Fall verläuft die Entwicklung des ökonomischen derjenigen des soziokulturellen Subsystems voraus. Die dadurch entstehenden Ungleichgewichte werden von Teilen der Bevölkerung als Überforderung empfunden, die sich in verschiedenen Stresssymptomen äußert. Angesichts des raschen sozioökonomischen Strukturwandels erscheint dies auf viele alpine Tourismusgebiete übertragbar (MEYRAT-SCHLEE 1982, S. 192; MüLLER 2001, S. 134f.). Mit einer nachholenden Anpassung des soziokulturellen Systems an den vollzogenen ökonomischen Strukturwandel sollten sich die Stressindikatoren wieder normalisieren (GUNTERN 1979, 1982), was KARIEL (1989, S. 64) bestätigt. Für Südtirol belegen RoHRER \& Rösch (2002, S. 109) diese gesellschaftliche Anpassung an den Tourismus und schreiben dem Generationswechsel eine wichtige Rolle zu. Die nachfolgende Generation hat eine touristische Ausbildung durchlaufen und ist im Gegensatz zur Aufbaugeneration nicht bereit, das Privatleben dem touristischen Betrieb völlig unterzuordnen.

Erst das zeitliche Zusammenfallen von Agrarstrukturwandel und massentouristischem Boom der Nachkriegszeit hat zu cultural-lag-Erscheinungen und damit soziokulturellen Problemlagen geführt (Niederer 1996, S. 132). Dieses Einfügen des Tourismus in tradierte Strukturen im Fall einer relativ langsamen, gleichmäßigen Entwicklung bestätigen auch Meleghy et al. (1987, S. 129ff.) für den Ort Vent im hinteren Ötztal, wo der Tourismus durch Zusatzeinkommen das Fortbestehen der traditionellen Agrarstruktur ermöglicht hat. Entscheidend ist nun die Intensität der touristischen Entwicklung, die im Rahmen der traditionellen Strukturen an Wachstumsgrenzen stößt, für deren Überschreiten eine Konzentration auf den Tourismus notwendig ist, die als „Folge von Handlungszwängen modern kapitalistische Handlungsorientierungen heraus[bildet]“ (Meleghy et al. 1987, S. 130). Dies wurde am Beispiel der Ortschaft Obergurgl herausgearbeitet. Einen Beleg für die Relevanz des Faktors „Intensität“ liefert auch die Studie von MöRTH (1997), der für die Tourismusgemeinden Oberösterreichs mit ihrer vergleichsweise geringen Tourismusintensität eine positive Wirkung auf die lokale Kultur im Vergleich zu nicht-touristischen Gemeinden nachweisen kann. Für die Gemeinden mit bis zu zehnfach höherer Tourismusintensität im Westen Österreichs sieht Mӧвтн (1997) jedoch die Grenzen der Sozial- und Kulturverträglichkeit deutlich überschritten. 
Zusammenfassend kann festgehalten werden, dass der Tourismus in den Alpen weniger als alleiniger Auslöser vielfältiger soziokultureller Entwicklungen betrachtet werden sollte - da er ,als entwicklungsbestimmender Faktor ... selten klar abgrenzbar [ist]“ (B ACHLEITNER \& PENZ 2000, S. 121) - , denn viel eher als „Verstärker und Beschleuniger gesamtgesellschaftlicher Veränderungsprozesse für ländliche Regionen“ (FIndL-Ludescher 1994, S. 195). Gleichzeitig betonen beide Autoren jedoch, dass sich die regionalen Identifikationsmuster und Selbstdarstellungen durchaus in Übereinstimmung mit der touristischen Nachfrage gewandelt haben (BACHLEITNER \& Penz 2000, S. 122). In die gleiche Richtung argumentiert Rest (1995, S. 82): Die vorgeblich vom Tourismus bedrohten kulturellen Identitäten seien überhaupt „erst durch Tourismus in der Form geschaffen w[o]rden, in der wir sie heute antreffen." (Zum Beispiel Gründung von Trachtenvereinen im späten 19. Jh. etc.). Für Geographen als Raumwissenschafter bedeutet dies, dass in der Folge der Fokus verstärkt auf den touristischen Einfluss auf die Kulturlandschaftsentwicklung gelegt werden sollte, da dort der touristische Einfluss eindeutiger (im Vergleich zu soziokulturellen Phänomenen) und konkret im Landschaftsbild nachweisbar ist.

Die Auswirkungen des Tourismus auf die alpine Kulturlandschaft resümierend, bleibt festzustellen: Vergleichbar den soziokulturellen Effekten ist offensichtlich, dass der Tourismus nicht der einzige Treiber des Kulturlandschaftswandels ist (ScHenK 2001, S. 30ff.). Insbesondere im Dauersiedlungsraum sind allgemeine Wirtschaftsund Bevölkerungsentwicklung, die Landwirtschaftspolitik samt Förderungen sowie das Verkehrswesen zumindest ähnlich starke Einflussfaktoren. Klar ist allerdings, dass in der vertikalen Dimension der touristische Einfluss auf die Kulturlandschaft sukzessive zunimmt, da andere Nutzungsalternativen zumeist wegfallen. Vor allem im Bereich bis zur Waldgrenze und auch noch in den alpinen Matten sind Land- und Forstwirtschaft von wesentlicher Bedeutung für das Landschaftsbild. Gerade was die Freihaltung talnaher Wiesen und Almflächen angeht, ist der Tourismus nicht in der Lage, einen Rückzug der Berglandwirtschaft zu kompensieren; er ist im Gegenteil von landwirtschaftlichen Vorleistungen abhängig. Dies führt zum nächsten Punkt. Der touristische Einfluss auf die Landschaft ist nur dort wirksam, wo sich geeignete Flächen zur Inwertsetzung finden, gute Erreichbarkeit gegeben ist und entsprechender Unternehmergeist gepaart mit dem notwendigen Kapital vorherrscht (LICHTENBERGER 1979, S. 401ff.; Englmaier et al. 1978, S. 41f.). Wie Abbildung 1 zeigt, ist dies bei weitem nicht in den gesamten Alpen der Fall.

Die wesentliche positive Wirkung des Tourismus auf die Kulturlandschaft der Alpen besteht in seiner im Idealfall symbiotischen Beziehung zur Berglandwirtschaft, der er ein dringend benötigtes zusätzliches Einkommen bietet und damit indirekt zum Erhalt von Teilen der traditionellen Agrarlandschaft beiträgt (RUPPERT 1963, S. 330). Dabei kann der touristische Nebenerwerb wiederum direkt oder indirekt erfolgen, d.h. entweder über eine Teilnahme der Landwirte am Beherbergungssektor (Urlaub auf dem Bauernhof) oder mittels einer Inwertsetzung der Almflächen (Skipisten) und Gebäude (Vermietung, Gastronomie). Dabei sind die Einnahmen und damit die Bedeutung des Tourismus für den Erhalt der Kulturlandschaft stark von der jeweiligen Intensität der touristischen Nutzung abhängig, wie MAYER et al. (2010) für den oberbayerischen Isarwinkel zeigen. 
Negativ auf die Kulturlandschaft wirkt sich der Tourismus durch Flächennutzungskonkurrenz mit der Landwirtschaft aus (zumeist in Tallagen). Auf der Almenstufe kann die zu starke Fokussierung auf touristische Nutzung zur Extensivierung und Vernachlässigung des landwirtschaftlichen Betriebszweiges führen, wogegen allerdings empirische Ergebnisse sprechen (ARNBERGER et al. 2006). Ebenfalls negativ zu bewerten sind die durch den Tourismus verursachten Schäden und Landschaftseingriffe, die zu einer Art technisierter und domestizierter „Dienstleistungslandschaft“ führen und die oben aufgeführten Nutzenkomponenten abwerten.

Zuletzt wirken sich die vom Tourismus beförderte Zersiedlungstendenz im Dauersiedlungsraum und die durch lokale Bauordnungen, Imitation, Innovationsdiffusion und commoditization bewirkte Uniformisierung von Ortsbildern nicht nur negativ auf die kulturlandschaftliche Identität der betreffenden Räume aus, sondern untergraben auch in einer Art negativer Rückkoppelung die touristische Attraktivität des Gebietes. Destinationen werden austauschbar, für Besucher entsteht keine Differenzerfahrung mehr (ANTONIETTI 1995, S. 118).

\section{Wirkungen des Tourismus auf die Kulturlandschaft der Alpen}

\subsection{Schematischer Wirkungszusammenhang differenziert nach Höhenstufen}

Generalisiert können die Wirkungen des Tourismus auf die Kulturlandschaft der Ostalpen in folgendem schematischen Profil zusammengefasst werden (vgl. Abb. 3). Klar ist, dass die Tourismusintensität und damit die Gestaltungskraft der damit zusammenhängenden Aktivitäten sowohl regional als auch saisonal erheblich schwanken. Des Weiteren gilt es auch den Höhengradienten mit einzubeziehen, denn die Tourismusgeschichte der Alpen belegt den hypsometrischen Trend einer stetig nach oben vordringenden Erschließung und freizeitsportlichen Nutzung (Јов 2005). Die saisonale Tourismusintensität bezieht sich dabei auf das raumzeitliche Freizeitverhalten und nicht auf den Übernachtungsstandort, der im Allgemeinen in den Talräumen liegt. Die Vergleichbarkeit der Tourismusintensität ist jeweils nur innerhalb einer Saison gegeben, da die infrastrukturellen Anforderungen der verschiedenen Freizeitaktivitäten stark divergieren. So zeigen Sommertouristen einen größeren Aktionsradius (z.B. bei Wanderungen) als dies bei der an Aufstiegshilfen und Skipisten gebundenen großen Mehrheit der Alpinskifahrer der Fall ist.

Talraum (collin-submontan): Die Täler werden generell vor allem als Verkehrsflächen (Parkplätze etc.), für tourismusanhängiges Gewerbe und für Freizeitinfrastruktur (Hallenbäder usw.) genutzt. Mit Ausnahme von Langlaufloipen und Winterwanderwegen findet die direkte Inanspruchnahme weniger durch winterliche Freizeitaktivitäten statt. Im Gegensatz dazu ist die sommerliche Nutzung umfänglicher und vielfältiger zugleich. Dazu rechnen: Tennisplätze, Fahrradwege, Wassersportarten auf alpinen Seen, Spaziergänge im Flachen und Aktivitäten wie Wein- und kulinarischer Tourismus (z.B. Törggelen in Südtirol) u.a.m. 


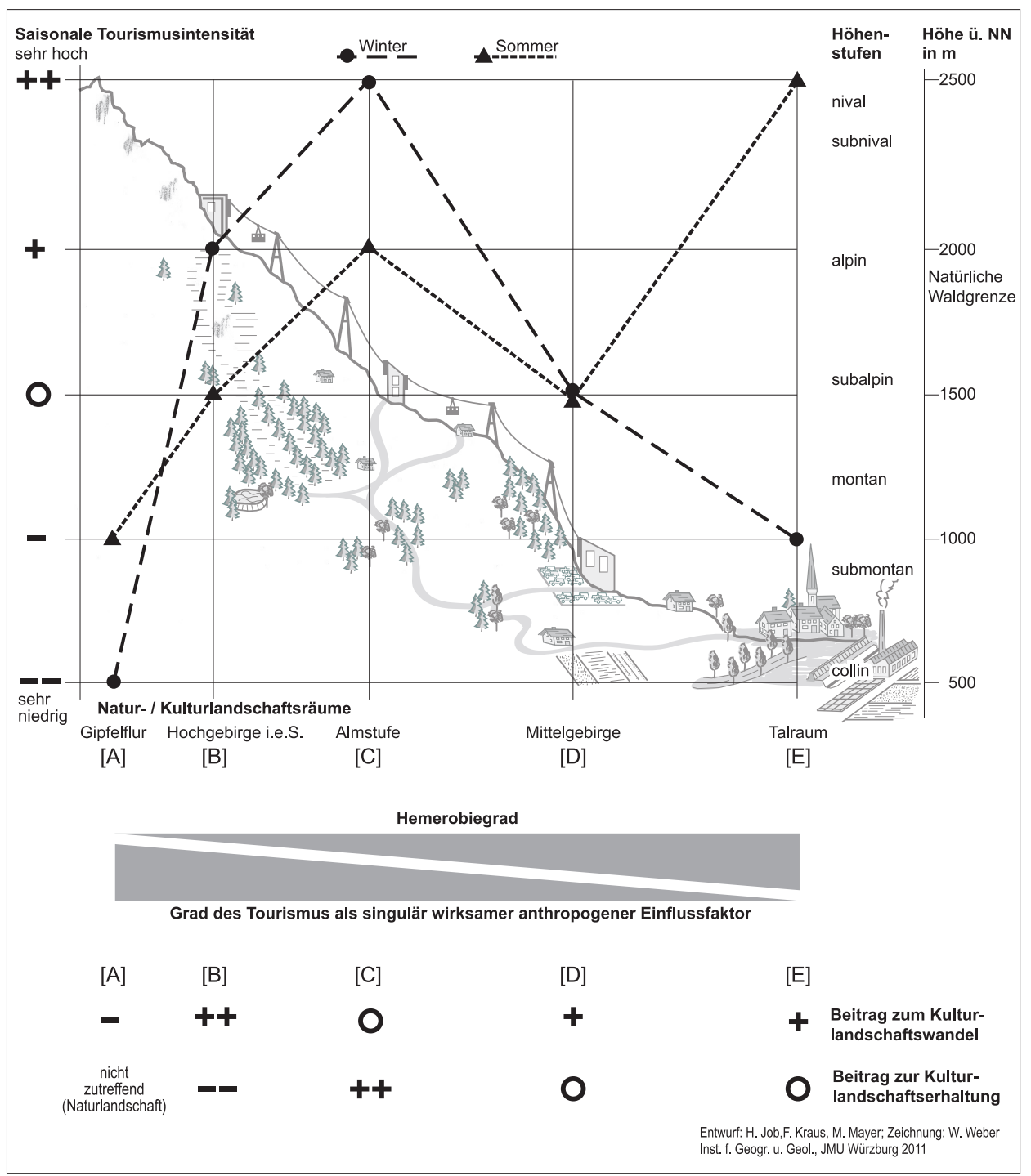

Quelle: Eigene Darstellung 2011

Abb. 3: Schematisches Profil zum Wirkungszusammenhang von Tourismus und Kulturlandschaft in den Ostalpen ${ }^{5)}$

\footnotetext{
5) Dieses Schema gibt vor allem Grundtendenzen wieder; es beruht nicht auf einer quantitativ-empirischen Aufnahme der Kulturlandschaft der Ostalpen, d.h. Ausnahmen oder gegensätzliche Ausprägungen sind wahrscheinlich.
} 
Mittelgebirge (montan): Die Höhenstufe der Mittelgebirge und höher gelegenen Täler wird in beiden Saisonen durchschnittlich intensiv genutzt. Im Winter liegt zumeist genügend Schnee für Langlauf und Schneeschuhtouren, im Sommer bieten die Sonnenbalkone und Plateaus Areale ohne die häufige Verkehrsbelastung der eigentlichen Talräume. Stark frequentierte Talabfahrten und Zubringerbahnen des Skitourismus führen durch diese Stufe.

Almstufe (కalpin): Die beliebteste Höhenstufe sommerlicher Wanderer ist die Almstufe, in der sich Lichtweide- und Waldflächen miteinander abwechseln und authentisch erscheinende Einkehrmöglichkeiten bieten. Auf die Almstufe konzentriert sich auch der Skitourismus, zumindest im ostalpinen Raum. So liegen derzeit in Tirol 58,8\% der Skipistenflächen zwischen 1.000 und 2.000 m Höhe (vgl. Tab. 2).

Hochgebirge i.e.S. ( $\geq$ subnival): Oberhalb der Almstufe befinden sich je nach Höhenerstreckung der Skigebiete bedeutende Pistenflächen; quantitativ und infrastrukturell wird die Intensität des sommerlichen Wandertourismus deutlich übertroffen.

Gipfelflur: Da mechanische Aufstiegshilfen zumeist nicht direkt auf Gipfeln enden, andernfalls als Ausflugsbahnen nicht die hohe Kapazität skitouristischer Beschäftigungsanlagen aufweisen und bei weitem nicht alle im Sommer erreichbaren Gipfel auch dankbare Skitourenziele abgeben, ist die sommerliche Intensität in der Gipfelflur höher als die winterliche, insgesamt dort aber am geringsten ausgeprägt.

Insgesamt betrachtet nimmt der Hemerobiegrad alpiner Landschaft, d.h. der Grad menschlicher Beeinflussung außermenschlicher Natur, mit zunehmender Höhe ab, wohingegen der Tourismus mit zunehmender Höhe als menschlicher Gestaltungsfaktor an Bedeutung gewinnt und zum Beispiel in den alpinen und nivalen Höhenstufen der einzige wirksame anthropogene Einfluss ist. ${ }^{6}$

Der untere Abschnitt von Abbildung 3 resümiert den Beitrag des Tourismus zum Kulturlandschaftswandel bzw. -erhalt:

Talraum (collin-submontan): In den Talräumen fällt die Bewertung der touristischen Einflüsse ambivalent aus, wenngleich weniger ausgeprägt als auf der Almstufe. Der Uniformisierung und Zersiedlung des Dauersiedlungsraumes verbunden mit Verkehrs(flächen)zunahme steht der positive Beitrag zum ökonomischen Überleben der Berglandwirtschaft mit ihren talnahen Flächen und Kulturdenkmälern gegenüber.

Mittelgebirge (montan): Im Mittelgebirge gewinnt der Tourismus an Einfluss auf die Kulturlandschaftsentwicklung, da andere Faktoren wie Siedlungsentwicklung oder der Verkehr zurücktreten und die Prägung durch Skitourismus und Zweitwohnungsbau zunimmt. Die positiven Wirkungen auf die Berglandwirtschaft treten hier jedoch genauso auf wie in der Talstufe.

Almstufe (<alpin): Auf der Almstufe ist die Wirkung des Tourismus am stärksten spürbar, wenngleich gegenläufig. Einerseits ist hier der am stärksten positive Beitrag des Tourismus zum Erhalt der traditionellen Kulturlandschaft durch vielfältige, positive Verknüpfungen beider Wirtschaftszweige wirksam. Andererseits gibt es gleichzeitig, wenn auch schwächere Eingriffe des Skitourismus, die touristische Inszenierung und Kommerzialisierung des Almbetriebs sowie den Bau skitouristisch motivierter Siedlungen in der Höhenlage als Beiträge zum Kulturlandschaftswandel.

\footnotetext{
6) Wenn man die Einflüsse von Luftschadstoffverfrachtungen in der unteren Atmosphäre außer Acht lässt.
} 
Hochgebirge i.e.S. ( $\geq$ subnival): Hier findet man einerseits den stärksten Einfluss des Tourismus in Sachen Kulturlandschaftswandel, gerade durch die in Kapitel 4.2.2 erläuterten Konsequenzen des Skitourismus. Da umgekehrt aber nur wenige Bereiche kulturlandschaftlich überformt sind - unter anderem bedingt durch die naturräumlichen Gegebenheiten - ist der Einfluss auf den Erhalt tradierter Strukturen sehr niedrig. Andererseits liegt dort und in der sich nach oben anschließenden Gipfelflur die Mehrzahl der strengen Naturschutzgebiete (vgl. Tab. 2), was sich unter anderem durch die hohe ökologische Sensibilität und mangelnde Flächennutzungskonkurrenz begründet.

Gipfelflur: Die Gipfelbereiche der Alpen sind gesamthaft gesehen wenig durch den Tourismus beeinflusst. Mit Aufstiegshilfen erschlossene Kammlinien werden zur Kulturlandschaft. In schwächerem Maße gilt dies für Hütten und Wanderwege sowie Klettersteige und -routen. Der Großteil der Alpengipfel ist bis dato dennoch Naturlandschaft geblieben.

In Kapitel 4.2 wird im Rahmen dreier Fallbeispiele auf die Wechselwirkungen zwischen Tourismus und alpiner Kulturlandschaft eingegangen.

\subsection{Fallbeispiele: Tourismus und Kulturlandschaft in den Alpen}

\subsubsection{Bergland- und Almwirtschaft}

Zwischen der Bergland- und Almwirtschaft und dem Tourismus besteht ein enges, wechselseitiges Abhängigkeitsverhältnis. Die Landwirtschaft schafft die Voraussetzungen für die touristische Attraktivität weiter Regionen durch Pflege der den Präferenzen der meisten Besucher entsprechenden Kulturlandschaft mit ihrem Wechsel aus Wald und Offenland, die dank ihrer orographischen sowie topographischen Lage attraktive Ausblicke bietet und sich ganzjährig für eine Reihe von Freizeitaktivitäten (Skifahren, Wandern) eignet. Aus soziokultureller Perspektive nehmen Almen die Rolle einer Sehnsuchtslandschaft ein, die als Gegenpol zur negativ stereotypisierten Großstadt konstruiert wird (MAYER et al. 2010, S. 64).

Die Beteiligung der Landwirtschaft am Tourismus kann verschiedene Formen in unterschiedlichen, sich teilweise überschneidenden Kombinationen annehmen. Bäuerliche Betriebe decken einen bedeutenden Teil des Beherbergungsangebots durch die Vermietung von Zimmern, Ferienwohnungen und das Angebot „Urlaub auf dem Bauernhof" ab. So sind beispielsweise 2.591 von 10.237 Beherbergungsbetrieben in Südtirol Bauernhöfe $(25,3 \%)$, die 9,8\% des Bettenangebots und 6,8\% (1,95 Mio.) der Übernachtungen im Tourismusjahr 2009/10 umfassen (ASTAT 2011, S. 18ff.). Im bayerischen Alpenraum bieten 25\% der Landwirte „Urlaub auf dem Bauernhof" an, in den Isarwinkler Gemeinden Lenggries und Jachenau 36\% bzw. 63\% (MAYER et al. 2010, S. 81f.).

Neben dem Talbetrieb können auch die Almen touristisch in Wert gesetzt werden. Dabei kann in direkte und indirekte Nutzung differenziert werden. Die direkte touristische Almnutzung ist als nach Nutzungs- und Kapitalintensität, Arbeits- und Infrastruktureinsatz, staatlichen Auflagen und Einkommensbeitrag abgestuftes Spektrum 
verschiedener Nutzungsformen zu verstehen, das von Tourenziel, der Vermietung/ Verpachtung von Almhütten, der Abgabe von Almprodukten, über den Verkauf von Getränken in geschlossenen Behältnissen bis hin zum Betrieb von Jausenstationen und Berggasthöfen mit vollwertiger Konzession reicht (MAYER et al. 2010, S. 64f.). Dabei zeigt sich eine stark linksschiefe Verteilung des ökonomischen Nutzens zu Gunsten der intensiven Formen, die auf einen eher exponentiell als linear ansteigenden Nutzen schließen lässt. Sobald eine Konzession mit allen damit verbundenen Auflagen besteht, ist von einem deutlichen Übergewicht der touristischen Nutzung auszugehen, während es sich bei Vermietung und der Abgabe von almeigenen Produkten in den meisten Fällen eher um einen willkommenen Zuverdienst als eine wirklich tragfähige Einkommensquelle handelt (MAYER et al.2010, S. 81). Insgesamt wiesen bei der letzten umfassenden Almerhebung in Österreich 1986 mehr als die Hälfte der Almen (6.801) touristische Einrichtungen auf. GreIF \& W AGNER (1995, S. 72) zu Folge profitieren etwa 4.000 bis 5.000 Almen in Österreich vom Tourismus. In Tirol werden ca. $60 \%$ der Almen direkt touristisch genutzt (ARnberger et al. 2006, S. 21). In einer empirischen Studie ermitteln MAYER et al. (2010) für den Isarwinkel und das Rissbachtal intraregional massiv abweichende Nutzungsintensitäten von Almen. Besonders große Bedeutung weist der Tourismus in verkehrsmäßig gut erschlossenen Almlandschaften in der Nähe belebter Destinationen - zwischen der Tourismusintensität und dem Anteil der Almfläche an der Gesamtkatasterfläche besteht eine hoch positive Korrelation (Pevetz 1998, S. 157) - und im Einflussbereich des Naherholungsverkehrs städtischer Zentren auf (Penz 1978, S. 100ff.; MAYER et al. 2010, S. 64).

Die ökonomisch bedeutendste indirekte touristische Almnutzung ist die Ausübung von Wintersportaktivitäten auf den Almwiesen, für die Landwirte Dienstbarkeitsabgeltungen oder Umsatzbeteiligungen der Betreibergesellschaften erhalten. Manche Almbauern betreiben aber auch selbst Skilifte. Zudem verlaufen die im nordischen Skisport genutzten Langlaufloipen oft auf landwirtschaftlichen Flächen (MAYER et al. 2010, S. 64). Der Skitourismus eröffnet zudem eine wichtige Nebenerwerbsmöglichkeit für Landwirte. Einen quantitativen Beleg bietet ein Blick ins Tiroler Zillertal, wo Anfang der 2000er Jahre von ca. 1.100 aktiven Landwirten (davon 139 Nebenerwerbsbauern) $12,6 \%$ bei den Seilbahnen direkt beschäftigt waren (WEChSELBERGER 2004). Die Skipistenfläche auf österreichischen Almen (12.000 ha, ca. 42\% von insgesamt 23.300 ha, Stand: 1999) multipliziert mit einem angenommenen mittleren Pachtsatz von $0,15 €$ pro $\mathrm{m}^{2}$ Pistenfläche ergibt für die Almeigentümer Pachteinnahmen von ca. 18 Mio. $€$ pro Jahr. Dazu kommen die Abgeltungen für Lifttrassenflächen (1.040 ha) in der Höhe von ca. 1,6 Mio. $€$. Somit werden in Österreich schätzungsweise knapp 20 Mio. Euro pro Jahr gezahlt (ArNBERGER et al. 2006, S. 36f.).

Die Land- und Forstwirtschaft im Berggebiet beeinflusst die Kulturlandschaft aber auch ohne direkten Bezug zum Tourismus: Insbesondere die Forstwirtschaft errichtet und unterhält ein weitgespanntes Straßennetz, das regional den Umfang touristischer Erschließungsmaßnahmen um ein Vielfaches übertrifft. Die nicht nur positiven Wechselwirkungen mit dem Tourismus und die ambivalente Rolle für die Kulturlandschaft (einerseits Eingriff, andererseits ermöglicht Wegebau den Fortbestand der Almwirtschaft) werden von MAYER \& Јов (2010) diskutiert. Zusammenfassend kann die wechselseitige Abhängigkeit von Tourismus und Berglandwirtschaft bezüglich der genutzten Flächen, 
der generierbaren Einnahmen und der Personal- bzw. Beschäftigungssituation (RINGLER 2009) als Synergieeffekt oder gar Symbiose bezeichnet werden, die trotz durchaus vorhandenen Störpotenzials als insgesamt positiv zu bewerten ist. KRIPPENDORF (1987, S. 23f.) führt als Beleg für die positive Wirkung des Tourismus auf die Berglandwirtschaft den im Vergleich zum Flachland verzögerten Strukturwandel an, den MAYER et al. (2010) für die bayerischen Alpen ebenfalls nachweisen. Die touristische Nutzung wird wegen des geringen landwirtschaftlichen Einkommens immer wichtiger und trägt beträchtlich zur Aufrechterhaltung der Bewirtschaftung bei, darf aber auch nicht überschätzt werden (RINGLER 2009). Das „Almensterben“ findet eher in touristisch wenig erschlossenen Gebieten Ostösterreichs und Teilen der italienischen Alpen statt, in denen auch die Waldflächenzunahme am stärksten ausfällt (GiUPPONI et al. 2006).

\subsubsection{Skitourismus}

Der Skitourismus erstreckt sich über beinahe sämtliche Höhenstufen der Alpen, hat jedoch (selbstverständlich abhängig von der jeweiligen Situation) klare Konzentrationen in den Höhenstufen der Almwirtschaft und den von ihr überprägten, natürlicherweise waldfreien alpinen Matten - Bereiche, die ohne größere Eingriffe skitouristisch nutzbar sind, weil keine zusätzlichen Rodungsarbeiten notwendig sind. Dies gilt auch für siedlungsnahe Talwiesenbereiche.

Auch in den Talräumen findet eine Überformung durch den Skitourismus statt. Vor allem wenn es keine traditionellen Höhensiedlungen oder diese imitierende Retortensiedlungen wie in den französischen Westalpen gibt, werden Pisten vom Tal aus durch kapazitätsstarke Zubringer erschlossen, an deren Talstationen sich Infrastruktur ballt. Mit der fortschreitenden Diffusion der technischen Beschneiung und deren Intensivierung wurden im letzten Jahrzehnt auch einige tief gelegene Talabfahrten reaktiviert (MAYER et al. 2007, S. 164). Kulturlandschaftlich nehmen sich die weißen Bänder in schneearmer Umgebung nach Meinung der Verfasser zumindest optisch befremdlich aus (das trifft in gleichem Maße auf die fallweise Beleuchtung von Talabfahrten zum Zweck des Angebots von Nachtskilauf zu) - wenngleich empirische Erhebungen betreffend ihrer Wahrnehmung durch Einheimische und Gäste fehlen. Im dichten Bergwald sind Rodungen und Geländekorrekturen notwendig, um massentaugliche Abfahrtsstrecken zu erhalten. Die zu skitouristischen Zwecken gerodeten Waldflächen stehen jedoch insgesamt in keinem Verhältnis zum gleichzeitig erfolgten Zuwachs bedingt durch die Auflassung von Grenzertragsflächen (Leitner 1984, S. 172). Aufgrund der relativ niedrigen Seehöhe kann sich die Vegetationsdecke innerhalb weniger Jahrzehnte zumindest optisch regenerieren, zumeist unterstützt durch landschaftsarchitektonische Begrünungsmaßnahmen.

Den prägendsten landschaftlichen Einfluss des Skitourismus in den letzten beiden Dekaden stellt die Herausbildung einer völlig neuen Beschneiungs-Kulturlandschaft dar, die das manifeste Resultat der flächenhaften Diffusion der technischen Beschneiung ist (Steiger \& MAYer 2008). Entlang der Skiabfahrten werden unter- und oberirdisch Leitungssysteme für Wasser, Strom und Druckluft eingerichtet sowie Schneeerzeuger (Propeller oder Lanzen) positioniert, die teilweise auch im Sommer stehen bleiben (PRÖBSTL 2006). In manchen Destinationen wird nach erfolgter Grundbeschneiung 
die gesamte Infrastruktur soweit wie möglich versteckt, anderen Ortens bleibt sie gut sichtbar für die Besucher stehen, möglicherweise als werbewirksamer Hinweis auf die Schlagkraft der Beschneiungsanlage ${ }^{7)}$ und die dadurch weitgehend technisch gesicherte Schneesicherheit. Dazu kommen dann noch Pumpenhäuser (im Französischen sinnigerweise mit, usine à neige" als Schneefabriken bezeichnet). In engem Zusammenhang mit der Installation von Beschneiungsanlagen steht das Planieren von Skipisten - sofern es nicht bereits bei der ursprünglichen Errichtung geschehen ist. Dies betrifft weniger Alm- und Mattenflächen als hochalpine Schutt- und Geröllhalden.

Aufgrund des hohen Wasserbedarfs wurde die Errichtung künstlicher Staubecken notwendig, die zunehmend die Größe veritabler Gebirgsseen einnehmen ${ }^{8}{ }^{8}$ Über die Wahrnehmung der künstlichen Wasserflächen durch verschiedene Nutzergruppen ist praktisch nichts bekannt. Teilweise sind die Speicher gut sichtbar und in die Landschaft integriert, teilweise werden sie vor allem unterirdisch ausgeführt (z.B. in den Südtiroler Dolomiten) oder in abgelegenen Bereichen. Sicher ist jedoch, dass manche Beschneiungsseen von den Betreibern in der Sommersaison als Ausflugs- und Wanderziele vermarktet werden. Dass die offensichtliche Künstlichkeit und Inszenierung Touristen nicht per se abschreckt, zeigt unter anderem der große Zulauf zu Hansi Hinterseers Open Air-Konzert 2008, das direkt am und auf dem Speichersee Ehrenbachhöhe auf $1.800 \mathrm{~m}$ stattfand (vgl. Abb. 4).

Diese Kunstschnee-Kulturlandschaft steht jedenfalls beispielhaft für die staged authenticity im Wintersporttourismus (Luger \& ResT 2002, S. 29f.). Wird in der Werbung zumeist das Stereotyp des einsamen Tiefschneefahrers angepriesen (vgl. Abb. 5), besteht die Realität aus einer high-tech Freizeitlandschaft aus technisch erzeugtem Schnee, Fangzäunen, Schaumstoffpolstern und Liftmasten. Eine ähnlich geartete Vorspiegelung von Authentizität ist in der Skihüttenkultur zu beobachten, die geschickt weit verbreitete Stereotype über Almen aufgreift, reproduziert und vermarktet (KIRCHENGAST 2008). Neue Bergrestaurants werden teilweise wie traditionelle Almhütten designt (nur eine Dimension größer), wobei sich die technische Ausstattung (wie z.B. Getränkeleitungen in den Keller) in der Fassade der back region verbirgt (Zeit Magazin 2010).

Auf Seiten der mechanischen Aufstiegshilfen setzt sich der seit Jahrzehnten bestehende Trend fort, mehrere kleinere Lifte durch wenige, dafür kapazitätsstärkere und zugleich komfortablere Anlagen zu ersetzen (MAYER 2009, S. 128f.). Die landschaftsästhetischen Konsequenzen sind zwiespältig. Negativ macht sich die geänderte Größendimension bemerkbar, mit massiveren Stations- und Stützenbauten, die oftmals weithin sichtbar sind, vor allem im Vergleich zu den ans Relief angepassten Schleppliften. Positiv wirkt sich die „Entrümpelung“ der Landschaft aus. Waren zum Beispiel am französischen Col de l'Iseran Mitte der 1970er Jahre noch zehn Anlagen

\footnotetext{
7) Die back region wird in diesem Fall also (un)bewusst der front region gleichgesetzt - nach dem Motto „what you see is what you get“- um durch diese Transparenz Glaubwürdigkeit für das Werbeversprechen „Schneesicherheit“ zu erlangen.

8) Der 2009/10 errichtete Speichersee Panorama am Ötztaler Tiefenbachferner auf $2.919 \mathrm{~m}$ Seehöhe weist $405.000 \mathrm{~m}^{3}$ Speicherkapazität auf. Die maximale Tiefe liegt bei $17 \mathrm{~m}$, die Dammhöhe bei $19 \mathrm{~m}$, die Wasserfläche beträgt $33.000 \mathrm{~m}^{2}$, die gesamten Erdbewegungen summieren sich auf $340.000 \mathrm{~m}^{3}$. Zur Abdichtung des Speichersees wurden 23.000 Tonnen Asphalt benötigt (BERGBAHNEN SöLdEn \& TECHNOALPIN 2010, S. 25).
} 


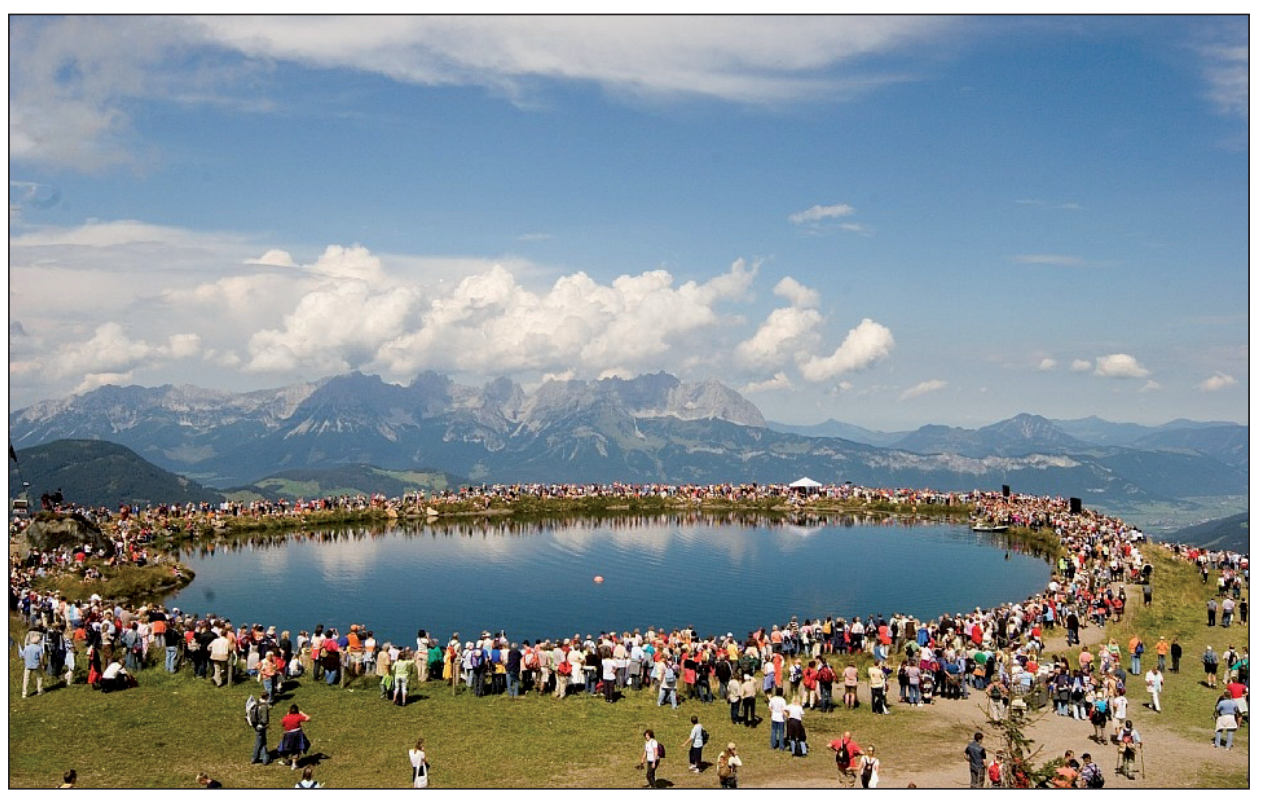

Quelle: Kitzbüheler Alpen Marketing GmbH, Kuenstleragentur Koenig und Agentur TexTour 2008

Abb. 4: Open-Air Konzert von Hansi Hinterseer am und auf dem Beschneiungsspeichersee Ehrenbachhöhe, Skigebiet Kitzbühel/Kirchberg in Tirol im Sommer 2008

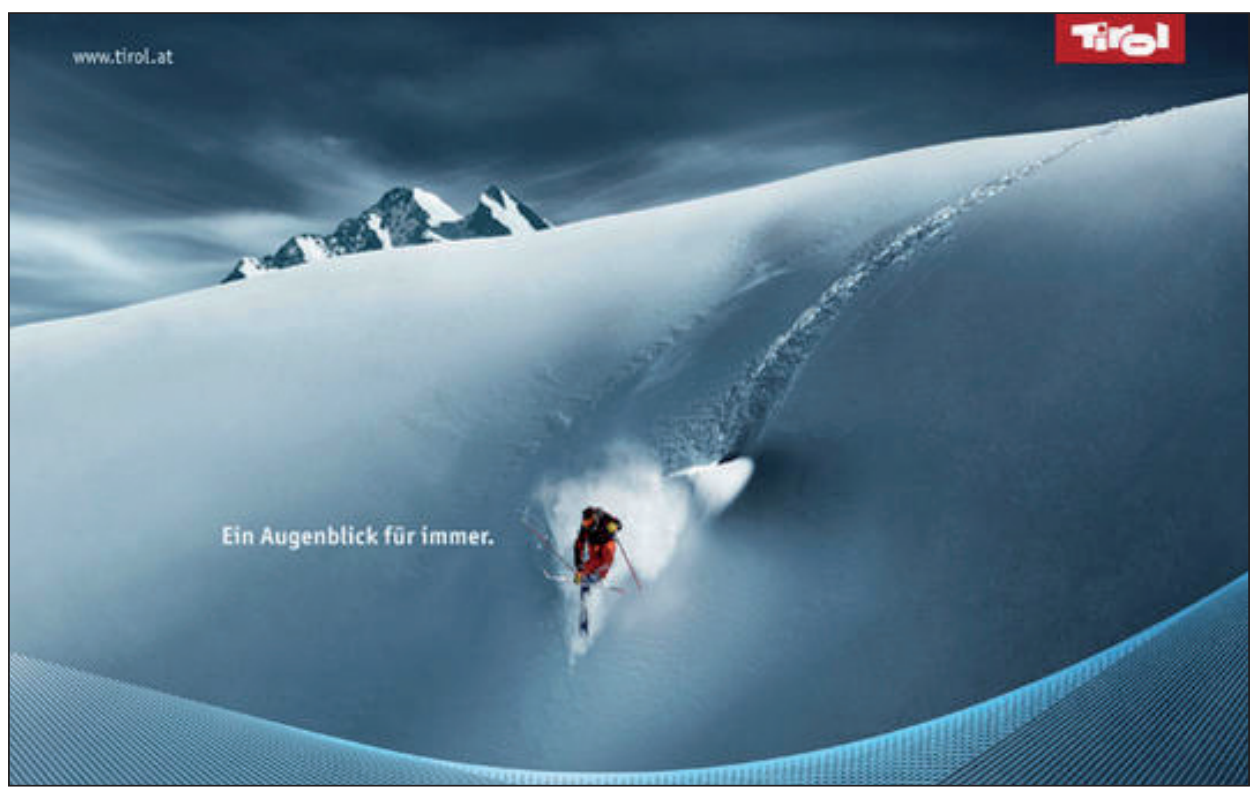

Quelle: Agentur Medialounge (Innsbruck) im Auftrag von Tirol Werbung 2010

Abb. 5: Werbung für Wintersporttourismus in Tirol 
installiert (Hannss 1974, S.94), wird heute die gleiche Pistenfläche von nur noch vier Liften bedient. Dieser Trend ist aber nicht überall feststellbar.

Die skitouristische Erschließung der Alpen ist bis auf Ausnahmen (insbesondere für Zusammenschlüsse von Skigebieten) abgeschlossen. Selbst im intensiv erschlossenen Tirol gibt es einige Gebiete, deren Anlagen nun entweder ausschließlich im Sommer genutzt werden oder gänzlich abgebaut wurden (vgl. Abb. 6). Der Grad des Rückbaus und der Renaturierung ist regional stark unterschiedlich und reicht vom Verrosten stillgelegter Anlagen ohne jede Veränderung (vor allem in Italien) bis hin zur aufwändigen Renaturierung. Als Musterbeispiel kann das Landschaftsrecycling des Gschwendtner Horns bei Immenstadt, Oberallgäu, Mitte der 1990er Jahre gelten (Dietmann \& Spandau 1996).

\subsubsection{Schutzgebiete als Gegenpole zu infrastrukturbasiertem Tourismus am Beispiel Tirols}

Nachdem im Kapitel 4.2.2 die landschaftlichen Wirkungen des Skitourismus allgemein behandelt wurden, soll nun eine räumlich differenzierte Betrachtung am Beispiel Tirols erfolgen, wobei Schutzgebiete als Ausgleichsräume den intensiv touristisch genutzten Gebieten gegenübergestellt werden .

Tirol ist eine der am intensivsten touristisch genutzten Regionen der Alpen, mit besonders hoher Bedeutung der Wintersaison (vgl. Abb. 1), was sich auch in der starken landschaftlichen Prägung durch die entsprechende Infrastruktur widerspiegelt. Abbildung 6 zeigt, wie stark der skitouristische Erschließungsgrad (als Flächenanteil) mit der geomorphologischen Eignung der Gebirgszüge korreliert (z.B. Kitzbüheler und Tuxer Schieferalpen versus Kalkstöcke Kaisergebirge, Karwendel; Samnaungruppe versus Kaunergrat und Geigenkamm; Ötztaler Hauptkamm versus Zillertaler Hauptkamm). Zudem belegen die Geodaten, ${ }^{9}{ }^{9}$ dass nur 4\% der Tiroler Landesfläche Skigebiete sind, wobei der Einflussbereich der Skifahrer deutlich größer ist (z.B. Variantenfahren). Differenziert nach Höhenstufen wird deutlich, dass $80 \%$ der Skigebietsflächen zwischen 1.000 und 2.500 Metern liegen, davon der größte Teil von annähernd $30 \% \mathrm{im}$ Bereich zwischen 1.500 und 2.000 Metern (vgl. Tab. 2).

Darüber hinaus gibt es enorme Unterschiede in der räumlichen Verteilung. Die höchsten Flächenanteile besitzen die Bezirke Kitzbühel und Landeck, die zusammen fast $45 \%$ der gesamten Skigebietsflächen umfassen. Es gibt auch Gebiete, die kaum von Skigebieten und den zugehörigen landschaftsverändernden Elementen beeinflusst sind, wie z.B. die Bezirke Lienz (1,2\% der Bezirksfläche), Innsbruck-Land (2,3\%) und Reutte $(2,5 \%)$.

Ein Viertel der Tiroler Landesfläche steht unter irgendeiner Art gesetzlichen Schutzes. Die strengen Schutzkategorien (vgl. Abb. 6: rote Signatur der Schutzgebiete) stehen im Allgemeinen dafür, Gebiete hoher Natürlichkeit zu erhalten und für weitgehend von Erschließungen freie Bereiche. Andere Schutzkategorien dienen häufig dem Erhalt der Kulturlandschaft, mit vielfältigen Landschaftselementen. In Ruhegebieten, als

\footnotetext{
9) Eigene Berechnungen anhand der Geodaten Skigebietsgrenzen Tiris 2005, Naturschutzrechtliche Festlegungen Tiris 2010 und dem DTM ASTER 2011.
} 


\begin{tabular}{|c|c|c|c|c|c|c|c|c|c|c|}
\hline \multirow{2}{*}{$\begin{array}{l}\text { Naturschutz- } \\
\text { rechtliche } \\
\text { Festlegungen }\end{array}$} & \multicolumn{8}{|c|}{ Höhenstufen in Metern } & \multirow[b]{2}{*}{$\Sigma$} & \multirow[b]{2}{*}{$\begin{array}{l}\text { Anteil } \\
\text { Fläche }\end{array}$} \\
\hline & $\begin{array}{c}0- \\
500\end{array}$ & $\begin{array}{c}501- \\
1.000 \\
\end{array}$ & \begin{tabular}{|l|}
$1.001-$ \\
1.500 \\
\end{tabular} & \begin{tabular}{|c|}
$1.501-$ \\
2.000
\end{tabular} & $\begin{array}{l}2.001- \\
2.500\end{array}$ & $\begin{array}{r}2.501- \\
3.000\end{array}$ & \begin{tabular}{|l}
$3.001-$ \\
3.500
\end{tabular} & $\begin{array}{r}3.501- \\
4.000\end{array}$ & & \\
\hline Imst & 0,0 & 1,8 & 1,5 & 7,2 & 23,9 & 43,8 & 21,8 & 0,2 & 100,0 & 19,1 \\
\hline Innsbruck & 0,0 & 4,7 & 21,6 & 40,3 & 32,0 & 1,4 & 0,0 & 0,0 & 100,0 & 1,6 \\
\hline Innsbruck-Land & 0,0 & 1,5 & 16,4 & 31,7 & 32,1 & 15,4 & 2,8 & 0,0 & 100,0 & 26,4 \\
\hline Kitzbühel & 0,0 & 25,1 & 44,9 & 28,2 & 1,9 & 0,0 & 0,0 & 0,0 & 100,0 & 4,0 \\
\hline Kufstein & 1,1 & 24,3 & 47,7 & 24,0 & 2,9 & 0,0 & 0,0 & 0,0 & 100,0 & 2,2 \\
\hline Landeck & 0,0 & 1,6 & 1,6 & 2,7 & 20,9 & 43,1 & 30,0 & 0,0 & 100,0 & 1,5 \\
\hline Lienz & 0,0 & 0,0 & 0,5 & 8,2 & 39,2 & 45,2 & 6,9 & 0,1 & 100,0 & 18,9 \\
\hline Reutte & 0,0 & 31,9 & 35,8 & 25,8 & 5,4 & 1,1 & 0,0 & 0,0 & 100,0 & 2,1 \\
\hline Schwaz & 0,0 & 2,9 & 27,7 & 29,4 & 23,2 & 15,3 & 1,6 & 0,0 & 100,0 & 24,1 \\
\hline Summe & $\mathbf{0 , 0}$ & 3,8 & 15,4 & 21,3 & 27,1 & 25,4 & 7,0 & $\mathbf{0 , 0}$ & 100,0 & $3.233,9$ \\
\hline $\begin{array}{l}\text { Skigebiets- } \\
\text { grenzen }^{10)}\end{array}$ & \multicolumn{8}{|c|}{ Höhenstufen in Metern } & & \\
\hline Polit. Bezirke & $\begin{array}{c}0- \\
500\end{array}$ & $\begin{array}{c}501- \\
1.000 \\
\end{array}$ & $\begin{array}{l}1.001- \\
1.500\end{array}$ & \begin{tabular}{|c|}
$1.501-$ \\
2.000 \\
\end{tabular} & \begin{tabular}{|c|}
$2.001-$ \\
2.500 \\
\end{tabular} & $\begin{array}{r}2.501- \\
3.000 \\
\end{array}$ & $\begin{array}{l}3.001- \\
3.500 \\
\end{array}$ & $\begin{array}{r}3.501- \\
4.000 \\
\end{array}$ & $\Sigma$ & $\begin{array}{l}\text { Anteil } \\
\text { Fläche }\end{array}$ \\
\hline Imst & 0,0 & 0,0 & 3,7 & 20,4 & 42,7 & 23,6 & 9,7 & 0,0 & 100,0 & 13,6 \\
\hline Innsbruck & 0,0 & 11,2 & 53,4 & 29,8 & 5,6 & 0,0 & 0,0 & 0,0 & 100,0 & $\mathbf{0 , 7}$ \\
\hline Innsbruck-Land & 0,0 & 2,5 & 27,1 & 34,1 & 16,3 & 17,0 & 2,9 & 0,0 & 100,0 & 9,1 \\
\hline Kitzbühel & 0,0 & 21,7 & 49,4 & 28,9 & 0,0 & 0,0 & 0,0 & 0,0 & 100,0 & 21,8 \\
\hline Kufstein & 0,0 & 29,4 & 48,0 & 22,6 & 0,0 & 0,0 & 0,0 & 0,0 & 100,0 & 7,1 \\
\hline Landeck & 0,0 & 0,2 & 7,9 & 36,0 & 43,0 & 12,5 & 0,4 & 0,0 & 100,0 & 22,6 \\
\hline Lienz & 0,0 & 2,4 & 20,5 & 41,3 & 35,0 & 0,8 & 0,0 & 0,0 & 100,0 & 4,6 \\
\hline Reutte & 0,0 & 2,4 & 68,4 & 26,4 & 1,8 & 1,0 & 0,0 & 0,0 & 100,0 & 6,2 \\
\hline Schwaz & 0,0 & 4,3 & 16,3 & 44,3 & 26,4 & 5,5 & 3,1 & 0,0 & 100,0 & 14,3 \\
\hline Summe & $\mathbf{0 , 0}$ & 8,1 & 26,8 & 32,0 & 22,5 & 8,5 & 2,1 & $\mathbf{0 , 0}$ & 100,0 & 509,4 \\
\hline
\end{tabular}

Quellen: Eigene Berechnungen nach Amt DeR TIROLER LANDESREgIERUnG-TIRIS 2005, 2010; ASTER 2011

Tab. 2: Flächenanteile der Tiroler Schutz- und Skigebietsflächen differenziert nach Höhenlage und Bezirken (Angaben in \%, Fläche in $\mathrm{km}^{2}$ )

\footnotetext{
${ }^{10)}$ Die Skigebietsgrenzen umfassen die Abgrenzungen der Tiroler Skigebiete wie sie im aktuell gültigen Tiroler Seilbahn- und Skigebietsprogramm 2005 festgelegt wurden: Diese Flächen entsprechen den von Seilbahnen und Skigebieten in Anspruch genommenen Geländekammern, die als „,erschlossene Gebiete“ landschaftlich in Erscheinung treten und in denen sich neben den Seilbahnen und Pisten auch weitere relevante Anlagen und Einrichtungen (z.B. Lawinenverbauungen, Wegerschließungen, Beschneiungsanlagen) befinden (vgl. Amt DER Tiroler LANDESREgIERUng 2005).
} 
ein Beispiel weniger strenger Schutzgebiete, befindet sich zwar keine skitouristische Infrastruktur, aber teilweise intensive energiewirtschaftliche Nutzung, z.B. in den Zillergründen. Generell lässt sich dennoch konstatieren, dass die Schutzgebiete als ausgleichende Gegenpole zu den stark erschlossenen Skigebieten wirken können.

Die differenzierten Zielsetzungen der Schutzgebiete sollten hierzu die verschiedenen Landschaftsteile und Höhenstufen gleichmäßig abdecken. Jedoch liegen die Schutzgebiete in Tirol zu mehr als $60 \%$ oberhalb von 2.000 Metern, wodurch die Tallagen und die untere Höhenstufe bis zu 2.000 Metern unterrepräsentiert sind. Bis zu 1.000 Metern Höhe wird nicht einmal 1\% der Landesfläche durch Schutzgebiete abgedeckt. Dies begründet sich durch die starke wirtschaftliche Inanspruchnahme der Tallagen. Dieses Bild setzt sich auch im Bereich zwischen 1.000 und 1.500 Metern fort, wo ebenfalls nur 4\% der Landesfläche unter Schutz stehen, was sich bei einem Landesflächenanteil dieser Höhenlage von 24\% recht bescheiden ausnimmt. Diese starke Konzentration der Schutzgebiete auf die oberen Höhenstockwerke kann entsprechend der worthless land theory nach RunTE (1977, S. 857) darauf zurückgeführt werden, dass diese Landesteile nur deshalb unter Schutz gestellt wurden, weil sie heute für keine andere ökonomische Inwertsetzung wie Besiedlung, Land- und Forstwirtschaft oder Skitourismus geeignet erscheinen. So ist die Nutzung des Karwendel auf die Forst-, Jagd- und Almwirtschaft und einige kleinere Skigebiete in den Randbereichen beschränkt.

Die Gegenüberstellung der Schutzgebiete und Skigebietsflächen nach Politischen Bezirken zeigt, dass das Verhältnis in Landeck und Kitzbühel besonders unausgewogen ausfällt. Landeck hat mehr als zweimal so große Flächen in Skigebieten als in Schutzgebieten und in Kitzbühel sind geringfügig mehr Flächen unter Naturschutz als die Fläche der Skigebiete ausmacht. Somit ergibt sich in diesen Bezirken eine stärkere Überprägung der Kulturlandschaft durch Skigebietsinfrastruktur ohne einen Ausgleich durch Naturschutz. In Innsbruck, Innsbruck-Land, Lienz und Schwaz ist die Belastung der Landschaft durch Skigebiete geringer und wird durch die größeren Naturschutzflächen deutlich relativiert.

Die Bewahrung der ökologischen, ästhetischen und gesellschaftlichen Werte der Kulturlandschaft kann keine museale Erhaltung bedeuten. Denn Veränderung ist Landschaft inhärent. Traditionelle Kulturelemente, die zur Identifikation und der Wiedererkennung beitragen, müssen erhalten bleiben. Neue Elemente, Formen und Funktionen müssen mit einem gesellschaftlichen Konsens gestaltet werden. In diesem Kontext können Biosphärenreservate aufgrund ihrer Rahmenbedingungen einen wertvollen Beitrag zur Weiterentwicklung von Landschaften im Sinne der Bevölkerung leisten. Die Zonierung erhält die Balance zwischen (wirtschaftlicher) Entwicklung und dem Erhalt von Natur- und Kulturlandschaft. Der bottom-up-Ansatz trägt dazu bei, die neuen Entwicklungen auf eine möglichst große Akzeptanzbasis zu stellen (KonOLD 2007, S. 18ff.). Als Beispiel eignet sich der Biosphärenpark Großes Walsertal in Vorarlberg, wo es gelingt, den MaB-Anspruch „Verbesserung des Verhältnisses Mensch-Biospäre“ durch die Schaffung von Leitbildern umzusetzen. Zudem wird der Biosphärenpark als Naturschutzinstrument und Instrument zur touristischen Entwicklung von der Bevölkerung wahrgenommen, sodass der Anspruch einer nachhaltigen Modellregion im Großen Walsertal in den Bereichen Energie, Tourismus und Landwirtschaft implementiert wird (Coy \& WeIXLBAumer 2009, S. 104f.). 


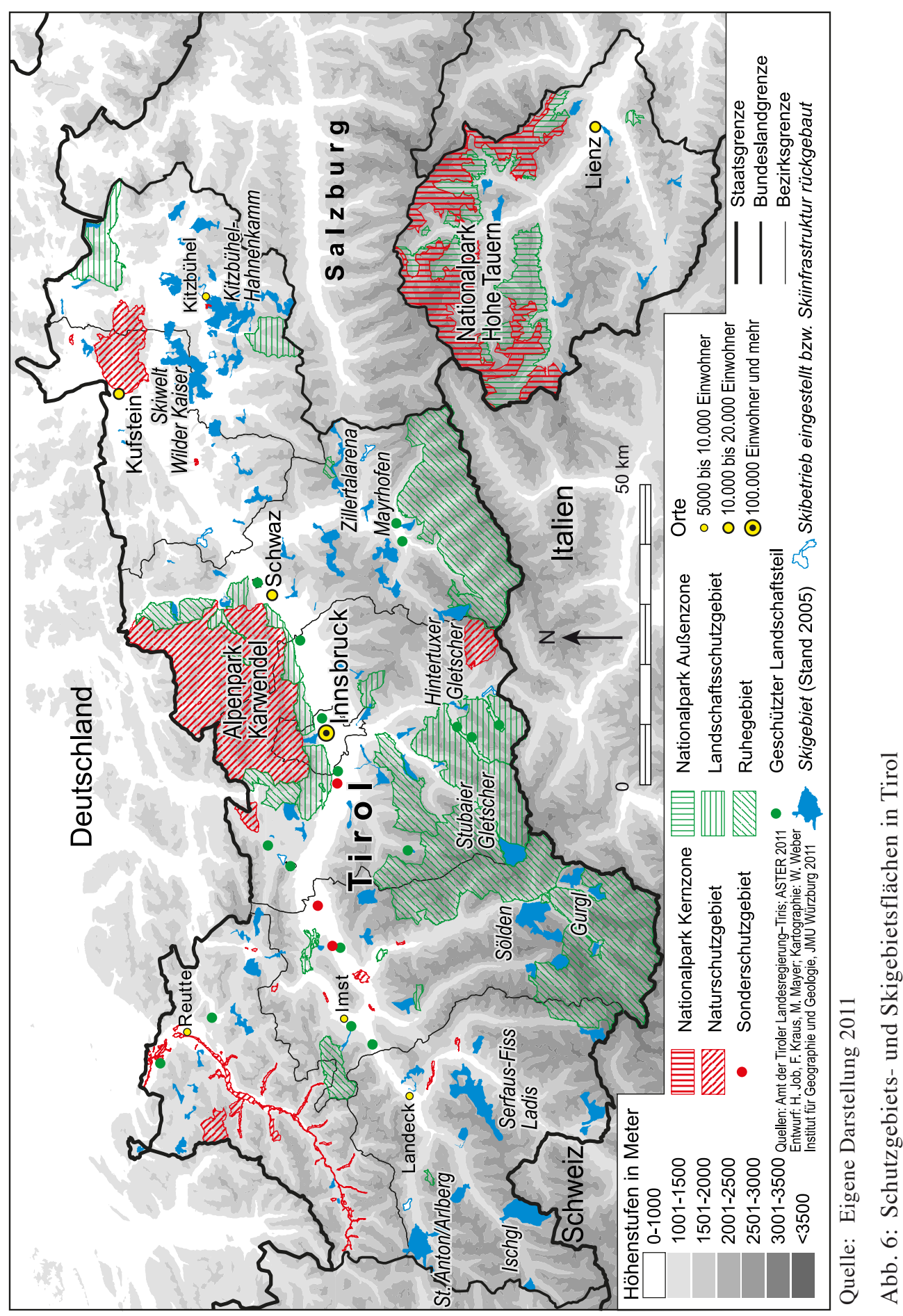




\section{Fazit und Ausblick}

Der Tourismus spielt seit Aufkommen des Massentourismus eine wesentliche Rolle, aber nicht immer und vor allem nicht flächendeckend die Hauptrolle beim Wandel der alpinen Kultur(landschaft). Neben allgemeinen gesellschaftlichen Modernisierungsund Globalisierungstendenzen, in der Hauptsache vermittelt durch die Massenmedien und die erhöhte individuelle Mobilität u.a.m., wirkt der Tourismus durch vermehrte Kontakte mit vor allem städtisch geprägten Gästen und internationalen Beschäftigten. Imitations- sowie Identifikationseffekte, Angleichung des Lebensstils ländlicher Regionen an die urbanisierten Zentren, Ausbildung einer eigenständigen Dienstleistungskultur und die damit in Zusammenhang stehende spezifische touristifizierte Kulturlandschaft sind die Konsequenzen. Dies trifft aber bei weitem nicht auf die gesamten Alpen zu, sondern nur auf gewisse Regionen und hängt bezüglich der Auswirkungen von den Dimensionen Zeit und Intensität ab. Eine kulturkritische Ablehnung des Tourismus und eine Zuschreibung kulturzerstörerischer Wirkungen kann pauschal nicht gelten. Die Uniformisierung des Dauersiedlungsraumes ist keineswegs allein tourismusbedingt: Gesichtslose Gewerbegebiete, konfektionierte Standardmärkte des Einzelhandels und dergleichen finden sich im Alpenvorland wie in den Alpen, in touristischen wie nichttouristisch geprägten Orten.

Auswirkungen des Tourismus auf Kultur und Kulturlandschaft der Alpen erfreuen sich derzeit offensichtlich kaum noch wissenschaftlicher Beachtung. Dafür lassen sich mehrere Erklärungsansätze finden:

- Die abflauende Kritik an den negativen Effekten des Alpentourismus kann mit der ökonomischen Abhängigkeit und Alternativlosigkeit vieler Alpenregionen erklärt werden, die insbesondere während der (vorübergehenden) Phase von Nächtigungsrückgängen (in Österreich in der ersten Hälfte der 1990er Jahre) vielen Akteuren offenbar wurden (Luger \& Rest 2002, S. 33).

- Für die Betroffenen mag sich im Lauf der Jahre ein gewisser Gewöhnungseffekt eingestellt haben. Präsenz von und Kontakt zu Touristen sind für die Bewohner der Alpen zur Normalität geworden. Durch eine professionelle Trennung von Vorderund Hinterbühne hat sich zudem der Problemdruck gemildert (vgl. Kap. 3).

- Kulturlandschaftlich sind in den letzten Jahren nicht mehr die (zum Teil durch raumordnerische Rahmensetzungen, verschärfte Umweltauflagen sowie verbesserte Naturschutzgesetzgebung eingedämmten) Negativwirkungen des Tourismus die Hauptproblemlage in den Alpen, sondern der quantitativ nachweisbare und zum Teil direkt beobachtbare Waldflächenzuwachs in großen Teilen des Gebirges. Dabei spielt auch die im Laufe der letzten Jahre aufgekommene Biodiversitätsthematik wegen der Artenvielfalt der verschwindenden Almwiesen und Bergmähder eine große Rolle. Zudem hat sich der Klimawandel samt seinen vielfältigen Folgen für die Alpen im letzten Jahrzehnt als Megathema schlechthin etabliert, befeuert durch direkt beobachtbare Konsequenzen für die Hochgebirgslandschaft (wie z.B. die Gletscherschmelze).

Als für die künftige Alpenforschung lohnende Desiderata können folgende Gesichtspunkte gelten: 
- Bislang fehlt eine Inventarisierung und flächenhafte Aufnahme der Beschneiungseinrichtungen: Die Anzahl, Größe, Lage und zeitliche Diffusion künstlicher Seen zu Beschneiungszwecken in den Alpen ist noch völlig unerforscht. Ebenso wäre eine Studie zu Umfang, Höhenlage und Begründungsfaktoren für Pistenplanien lohnenswert. Beide Fragestellungen könnten eventuell mithilfe von Methoden der Fernerkundung in größeren Raumausschnitten untersucht werden. Zur selben Thematik gibt es zudem nur wenige, die Nachfrageseite und Wahrnehmungsfragen betreffende Arbeiten.

- Im Gegensatz zur häufig postulierten, fortgesetzten touristischen Erschließung der Alpen ist den Autoren bislang keine Erfassung der geschlossenen und/oder rückgebauten Skigebiete der Alpen bekannt: Wie viele Gebiete betrifft es? Wo liegen diese? Welche Charakteristika sind ihnen eigen? Aus welchem Grund wurde der Betrieb eingestellt? Wie sehen Konversionsprojekte aus? Eine solche Erfassung sollte besonders vor dem Hintergrund künftiger Klimaerwärmung und den somit veränderten Konkurrenzbeziehungen skitouristischer Destinationen bald in Angriff genommen werden.

- Es gibt einen Mangel an quantitativ aussagekräftigen, destinationsübergreifenden, zeitlich als Längsschnitt angelegten Studien über die soziokulturellen Auswirkungen des Tourismus in den Alpen, die sich an einem der in Abbildung 2 vorgestellten Analyse-Konzepte orientieren. Diese Studien müssten aber auch qualitativ angelegt sein, um die notwendige Tiefenschärfe zu erreichen.

- Für den französisch-, italienisch- und slowenisch-sprachigen Alpenraum fehlt eine diesem Beitrag vergleichbare Zusammenstellung der Auswirkungen des Tourismus auf die Kultur(landschaft).

- Von Seiten der Neuen Kulturgeographie wäre eine Aufarbeitung öffentlicher Diskurse über Erschließungen zur Untersuchung möglicher nationaler (West- versus Ostalpen) und regionaler Unterschiede von großem Interesse; werden doch zum Beispiel in Tirol selbstverständliche Attraktionspunkte wie Aussichtsplattformen an Bergstationen in Oberbayern kritisch diskutiert und von Protest begleitet, während im Nachbarland dergleichen nicht festzustellen ist.

Abschließend stellt sich die Frage, ob eine angemessene Beurteilung der untersuchten Effekte mit den vorgeschlagenen Zugangsweisen überhaupt zu leisten ist. Es könnte argumentiert werden, dass die in der Alpenforschung seit längerem vertretene und hier fortentwickelte These der Ambivalenz (Gleichzeitigkeit und Differenz) alpiner Entwicklungen nach höher aufgelösten Methoden und einer noch entschiedeneren Differenzierung verlangte - mit Blick auf „Kultur“ auch nach dem Einsatz stärker qualitativ und historisch-sozialwissenschaftlich argumentierender Zugänge. Diese Frage ist nicht eindeutig zu beantworten. Großmaßstäbige, qualitative Ansätze sind zur Aufdeckung alpenweiter Phänomene wegen mangelnder Übertragbarkeit und zweifelhafter Repräsentativität nur in Maßen zweckmäßig, gleichwohl aber, wie in den in Tabelle 1 aufgeführten Fallstudien ersichtlich, für den jeweiligen Untersuchungsraum durchaus erkenntnisstiftend. Die in Abbildung 2 vorgestellten konzeptionellen Ansätze zur Analyse der Auswirkungen des Tourismus auf die alpine Kultur erscheinen dazu tauglich, müssten jedoch in empirischen Untersuchungen angewandt werden. Zur Beantwortung der Forschungsfrage wird das Vorgehen weiterhin als geeignet angesehen, 
da die ausführliche Literatur-Auswertung den Stand der Forschung wiedergibt und damit die Ambivalenz und Widersprüchlichkeit der Entwicklungen aufzeigt. Festzuhalten bleibt, dass man bei allgemeinen Bewertungen Vorsicht walten lassen muss, zum Zweck wissenschaftlicher Transparenz die Bewertungskriterien und -perspektiven (Wer bewertet was, wann, zu welchem Zweck?) offen legen und die jeweilige Situation vor Ort genau untersuchen sollte.

\section{Literaturverzeichnis}

ACHLEITNER F. (1977), Über das Verhältnis von Bauen und Landschaft. In: Achleitner F. (Hrsg.), Die Ware Landschaft. Eine kritische Analyse des Landschaftsbegriffs, S. 127-133. Salzburg, Residenz-Verlag.

ACHLeitner F. (1986), Österreichische Architektur im 20. Jahrhundert - ein Führer in drei Bänden. Oberösterreich, Salzburg, Tirol, Vorarlberg. Salzburg, Residenz-Verlag.

Agentur Medialounge (Innsbruck) im Auftrag von Tirol Werbung (Hrsg.) (2010), Tirol - Ein Augenblick für immer. - http://www.wuv.de/layout/set/print/nachrichten/unternehmen/ client_award_2010_shortlist_anzeige/kontakter_client_award_2010_shortlist_anzeigel kontakter_client_award_2010_shortlist_anzeige10 (Abrufdatum 11.07.2011)

Amt der Tiroler Landesregierung - Tiris (Hrsg.) (2005), Schigebietsgrenzen Stand 2005. Geodaten-Satz, frdl. pers. Mittlg.

Amt der Tiroler Landesregierung (Hrsg.) (2005), Tiroler Seilbahn- und Skigebietsprogramm 2005. - http://www.tirol.gv.at/themen/landesentwicklung/raumordnung/ueberoertliche/ seilbahnprogramm (Abrufdatum 14.09.2011)

Amt der Tiroler Landesregierung - Tiris (Hrsg.) (2010), Naturschutzrechtliche Festlegungen Stand 2010. Geodaten-Satz, frdl. pers. Mittlg.

AndexLinger W. et al. (2005), Tirol City - Neue Urbanität in den Alpen. Wien - Bozen, Folio Verlag.

ANFT S. (1993), Die Studie „Alpendorf“. Auswirkungen des Massentourismus auf das ökonomische und soziale System eines Bergdorfes. In: Hahn H., Kagelmann H.J. (Hrsg.), Tourismuspsychologie und Tourismussoziologie: ein Handbuch zur Tourismuswissenschaft, S. 577-582. München, Quintessenz-Verlag.

Antonietti T. (1995), Vom Hotel in den Bergen zur alpinen Erlebnislandschaft. In: Luger K., Inmann K. (Hrsg.), Verreiste Berge - Kultur und Tourismus im Hochgebirge, S. 109-124. Innsbruck, Studien-Verlag.

Arnberger A., Muhar A., Sterl P. (2006), Auswirkungen des Tourismus (= AlP Austria Programm z. Sicherung u. Entwicklung d. alpinen Kulturlandschaft. Endbericht zum Teilprojekt 17). - http://www.almwirtschaft.com/images/stories/fotos/alpaustria/pdf/ ArnbergerMuharSterl_Tourismus.pdf(Abrufdatum 14.01.2008)

ASter (Advanced Spaceborne Thermal Emission and Reflection Radiometer) (Hrsg.) (2011), Digital Terrain Model. Pasadena.

Autonome Provinz Bozen-Südtirol (Hrsg.) (2009), Aufenthaltssteuer auf Zweitwohnungen erhöhen. - http://www.provinz.bz.it/lpa/285.asp?redas=yes\&aktuelles_action=4\&aktuelles_ article_id=308884 (Abrufdatum 04.06.2011)

Autonome Provinz Bozen-Südtirol (Hrsg.) (2010), Kulturlandschaft Südtirol. Der Wandel seit 1950. Bozen.

Autonome Provinz Bozen-Südtirol - Landesinstitut für Statistik (ASTAT) (Hrsg.) (2011), Tourismus in Südtirol. Tourismusjahr 2009/10. Bozen. - http://www.provinz.bz.it/astat/ 
de/mobilitaet-tourismus/471.asp?Tourismus_action=4\&Tourismus_article_id=167595 (Abrufdatum 04.06.2011)

B ACHLEITNER R. (1997), Suizid durch Tourismus - Faktum oder Fiktion? In: Tourismus Journal, 1,2 , S. 225-238.

B ACHLEITNER R., Penz O. (2000), Massentourismus und sozialer Wandel. Tourismuseffekte und Tourismusfolgen in Alpenregionen (= Tourismuswiss. Manus., 10), München - Wien, Profil Verlag.

B ARBER B.R. (2003), Jihad vs. McWorld. Terrorism's Challenge to Democracy. London, Random House.

B ÄTZING W. (2002), Der Stellenwert des Tourismus in den Alpen und seine Bedeutung für eine nachhaltige Entwicklung des Alpenraumes. In: Luger K., Rest F. (Hrsg.), Der Alpentourismus. Entwicklungspotenziale im Spannungsfeld von Kultur, Ökonomie und Ökologie, S. 175-196. Innsbruck, Studien-Verlag.

Bätzing W. (2003), Die Alpen. München, Beck.

В ̈̈тZING W. (2009) [2002], Was bedeutet „Alpenkultur“? Ein zentrales politisches Thema der Alpenkonvention. In: Hanzig-B Ätzing E. (Hrsg.), Orte guten Lebens. Die Alpen jenseits von Übernutzung und Idyll. Einsichten und Einmischungen aus drei Jahrzehnten, S. 295-314. Zürich, Rotpunktverlag.

BENDER O. (2005a), Vom ersten und zweiten Wohnen. Wohnform und Wohnnutzung. In: BorsDORF A. (Hrsg.) (2005), S. 126-127.

Bender O. (2005b), Städtisches Leben im Vormarsch. Urbanisierung und Nahversorgung. Borsdorf A. (Hrsg.) (2005), S. 118-119.

Bender O., Schumacher K.P., Stein D. (2007), Tourism and seasonality in Central Europe. In: Palang H., Sooväli H., Printsmann A. (Hrsg.), Seasonal Landscapes (= Springer Landscape Series, 7), S. 181-214. Heidelberg, Springer.

Bergbahnen Sölden, TechnoAlpin AG (Hrsg.) (2010), Backstage Magazin. Söldens Schneegarantie.-http://www.soelden.com/main/files/Soelden/BBS/backstage_schneegarantie. $p d f$ (Abrufdatum 01.12.2010)

Bieger T., Beritelli P. (2004), Zweitwohnungen - Chancen und Gefahren eines Phänomens. In: IDT-Blickpunkt, 11, S. 5-6.

Bовек H. (1957), Gedanken über das logische System der Geographie. In: Jahrbuch d. Österr. Geogr. Ges., 99, S. 122-145.

Borsdorf A. (Hrsg.) (2005), Das neue Bild Österreichs. Strukturen und Entwicklungen im Alpenraum und in den Vorländern. Wien, Verlag d. ÖAW.

Borsdorf A. (2005), Überleben durch Tourismus. Zur Siedlungsentwicklung in entlegenen Alpentälern. In: Borsdorf A. (Hrsg.) (2005), S. 130-131.

Borsdorf A., Bender O. (2007), Kulturlandschaftsverlust durch Verbuschung und Verwaldung im subalpinen und hochmontanen Höhenstockwerk: Die Folgen des klimatischen und sozioökonomischen Wandels. In: InNSBRucKer Geographische Gesellschaft (Hrsg.), Alpine Kulturlandschaft im Wandel, S. 29-50. Innsbruck.

Brugger O., Wohlfarter R. (1983), Alpwirtschaft heute. Graz, Stocker Verlag.

Brougham J., Butler R. (1981), A Segmentation Analysis of Resident Attitudes to Social Impacts of Tourism. In: Annals of Tourism Research, 7, 4, S. 569-590.

BundesAmt FÜR BAuwesen und RAumordnung (Hrsg.) (2001), Kriterien für die räumliche Differenzierung des EU-Territoriums: Kulturerbe (= Forschungen, 100.1). Bonn.

Butler R.W. (1980), Concept of a Tourist Area Cycle of Evolution: Implications for Management of Resources. In: Canadian Geographer, 24, 1, S. 5-12.

CernusCa A. (1977), Schipisten gefährden die alpine Gebirgslandschafts. In: Umschau, 77, S. 109-112.

Cipra (Hrsg.) (2008), Viel Raum für wenig Nutzen. Zweitwohnungsbau im Alpenraum. Ein Hintergrundbericht. Schaan. - http://www.cipra.org/pdfs/590_delat_download/file (Abrufdatum 01.05.2011) 
Cohen E. (1984), The sociology of tourism. Approaches, issues, and findings. In: Annual Review of Sociology, 20, S. 373-392.

Conrad K. (1994), Tourismus und alpine Baukultur. In: Pöttler B., Kammerhofer-AggermanN U. (Hrsg.), Tourismus und Regionalkultur, S. 277-284. Wien, Selbstverlag d. Vereins f. Volkskunde.

Coy M., Weixlbaumer N. (2009), Die Untersuchungsergebnisse und ihre Bedeutung für die künftige Entwicklung des Biosphärenparks Großes Walsertal - Zusammenfassung und Interpretation. In: Coy M., WeIXLBAumer N. (Hrsg.), Der Biosphärenpark als regionales Leitinstrument. Das Große Walsertal im Spiegel der Nutzer (= alpine space - man \& environment, 10), S. 95-108. Innsbruck, Innsbruck Univ. Press.

DAV (Deutscher Alpenverein) (Hrsg.) (2010), Position des DAV zu neuen touristischen Attraktionen in den bayerischen Alpen: Alpen dürfen nicht zur Kulisse werden. - http:// cms.alpenverein.deldownload_file.php? id=6702\&showfile $=1$ (Abrufdatum 01.06.2011)

Decker H. (2001), Wer braucht die Piefkes? In: Berge, 3 Mai/Juni, S. 60-64.

Dietmann T., Spandau L. (1996), Renaturierung eines Skigebietes. Beitrag zu einem sanften Tourismus im Alpenraum? In: Geogr. Rundschau, 48, 3, S. 152-158.

Dietmann T., Kohler U., Lutz G. (2005), Die Skigebiete in den bayerischen Alpen. Ökologischer Zustand, Konfliktbereiche, Lösungsmöglichkeiten - eine Schlussauswertung der Skipistenuntersuchung Bayern. In: Jahrbuch d. Vereins z. Schutz d. Bergwelt, 70, S. 45-60.

DworschaK H. (1994), Kulturdiskurse. Zum Verhältnis von Tourismus und indigener Kultur. München, Waxmann Verlag.

Eder P., Kurka N., Zimmermann F.M. (2005a), Touristisches Angebot. Kommerzialisierung der Beherbergungsstruktur. In: Borsdorf A. (Hrsg.) (2005), S. 140-141.

Eder P., Kurka N., Zimmermann F.M. (2005b), Privatquartiere im Tourismus. „Klassische“ Privatzimmer plus Ferienwohnungen/-häuser. In: Borsdorf A. (Hrsg.) (2005), S. 142-143.

Englmaier A. et al. (1978), Strukturdaten der Alm- und Alpwirtschaft in Bayern. Ergebnisse der Alm- und Alperhebung 1976 (= Schriftenreihe d. Alpeninst., 9). München, Geobuch-Verlag.

ERlacher R. (2008), Nostra Culpa: Wie wir Naturschützer die Bergwelt des Karwendels am Rande der Karwendelgrube im Cyberspace versenkt haben. In: Jahrbuch d. Vereins z. Schutz d. Bergwelt, 73, S. 84-105.

FindL-Ludescher H. (1994), Leben im Tourismus. Tourismus und Identität. Thaur, KulturVerlag.

FrEI H. (1970), Der Fremdenverkehr in seiner Bedeutung für die Bergbevölkerung am Beispiel von Damüls im Bregrenzer Wald. In: Mitt. d. Geogr. Ges. in München, 55, 2, S. 135-154.

GiUPPONI C. et al. (2006), Climate and land use changes, biodiversity and agri-environmental measures in the Belluno province, Italy. In: Environmental Science and Policy, 9, 2, S. 163-173.

Goffman E. (19834) [1959], Wir alle spielen Theater. Die Selbstdarstellung im Alltag. München, R. Piper \& Co. Verlag.

GrABHERR G. (1987), Tourismusinduzierte Störungen, Belastbarkeit und Regenerationsfähigkeit der Vegetation in der alpinen Stufe. In: Patzelt G. (Schriftleitung), MaB-Projekt Obergurgl (= Veröff. d. Österr. MaB-Programms, 10), S. 243-256. Innsbruck, Univ.-verlag Wagner.

GREIF F. (1987), Wintersporteinrichtungen und ihre Auswirkungen auf die Land- und Forstwirtschaft (= BA f. Agrarwirtschaft Schriftenreihe, 47), Wien.

Greif F., Riemerth A. (2006), Gesamtökonomische Bedeutung der Almen Österreichs (= ALP Austria Programm zur Sicherung und Entwicklung der alpinen Kulturlandschaft). - http:// www.almwirtschaft.com/images/stories/fotos/alpaustria/pdf/GreifRiemerth_Gesamtwirt schaftlicheBedeutung.pdf (Abrufdatum 14.01.2008).

Greif F., W AGNER K. (1995), Kooperation L\&T. Zusammenarbeit von Landwirtschaft, Tourismus und Freizeitwirtschaft. Wien, Fachverband d. Seilbahnen u. Bundessektion Tourismus u. Freizeitwirtschaft d. Wirtschaftskammer Österreich. 
Groier M. (1993), Bergraum in Bewegung. Almwirtschaft und Tourismus - Chancen und Risiken (= BA f. Bergbauernfragen Forschungsbericht, 31). Wien.

Guntern G. (1979), Social change, stress and mental health in the Pearl of the Alps. Berlin, Springer.

Guntern G. (1982), Die Perle der Alpen: Sozio-ökonomische, sozio-kulturelle und gesundheitspolitische Aspekte des sozialen Wandels in Saas-Fee. In: KripPendorf J., Messerli P., Hänni H. (Hrsg.), Tourismus und regionale Entwicklung, S. 157-180. Diessenhofen, Rüegger.

HAAS-Frey V. (1976), The Impact of Mass Tourism on a Rural Community in the Swiss Alps. Unveröff. Diss., Dept. of Anthropology, Univ. of Michigan.

HAID H. (1994), ... immer höher, am höchsten, am größten - und andere folkloristische Superlative. In: Haid G., Haid H. (Hrsg.), Brauchtum in den Alpen. Riten, Traditionen, lebendige Kultur, S. 253-257. Bad Sauerbrunn, Rosenheimer-Verlag.

HALLER R., LingG A. (1985), Vorarlberger Suizidstudie. Bregenz, Eigenverlag d. Vorarlberger Landesregierung.

Hanisch E. (1994), Wirtschaftswachstum ohne Industrialisierung. Fremdenverkehr und sozialer Wandel in Salzburg 1918-1938. In: HaAs H., HoffmannN R., Luger K. (Hrsg.), Weltbühne und Naturkulisse. Zwei Jahrhunderte Salzburg-Tourismus, S. 104-112. Salzburg, Pustet.

Hannss C. (1974), Val d'Isère. Entwicklung und Probleme eines Wintersportplatzes in den französischen Nordalpen (= Tübinger Geogr. Studien, 56). Tübingen, Selbstverlag d. Geogr. Inst. d. Univ. Tübingen.

Hannss C., SChröDer P. (1985), Touristische Transportanlagen in den Alpen. Bedeutung, Merkmale und räumliche Verteilung der mechanischen Aufstiegshilfen. In: DISP, 79, S. 19-25.

Herdin T., Luger K. (2001), Der eroberte Horizont. Tourismus und interkulturelle Kommunikation. In: Aus Politik u. Zeitgeschichte B47/2001, S. 6-19. - http://www.bpb.delfiles/ H2Y41E.pdf (Abrufdatum 28.05.2011)

Herskovits M. (1937), The Significance of the Study of Acculturation for Anthropology. In: American Anthropologist, 39, 2, S. 259-264.

HöGL H. (1995), Hinter den Fassaden des Tourismus - Dörfer im Stress. Innsbruck, Studien-Verlag.

HöGL H. (2002), Bin kein Tourist, ich wohne hier. Fremdenverkehrsgemeinden im Streß. Wien, Verlag f. Ethik+Ges.

Höllbacher R., Rieder M.M. (1995), Die Beliebigkeit der Zeichen. Bemerkungen zur Ästhetik von Landschaft und Architektur im Tourismus. In: Luger K., InMann K. (Hrsg.), Verreiste Berge - Kultur und Tourismus im Hochgebirge, S. 125-141. Innsbruck, Studien-Verlag.

Hunziker M., Buchecker M., Hartig T. (2007), Space and Place - Two Aspects of the Humanlandscape Relationship. In: Kienast F., Wildi O., Ghosh S. (Hrsg.), A Changing World, S. 47-62. Dordrecht, Springer.

ICKeRoDt U.F. (2007), Die räumliche Dimension der Geschichte: Kulturlandschaft als Ort der historischen Wissensvermittlung. In: Bauerochse A., Hassmann H., ICKerodt U.F. (Hrsg.), Kulturlandschaft - administrativ - digital - touristisch, S. 255-278. Berlin, Erich-Schmidt-Verlag.

JäGER H. (1987), Entwicklungsprobleme europäischer Kulturlandschaften. Darmstadt, Wiss. Buchges.

JAFARI J. (1982), Understanding the Structure of Tourism - An Avant Propos to Studying its Costs and Benefits. In: AIEST (Hrsg.), Wechselwirkungen zwischen Nutzen und Kosten des touristischen Angebots. Berichte anl. d. 32. AIEST-Kongresses vom 12. bis 19. September 1982 in Zagreb, Plitvice und Zadar, S. 51-72. St. Gallen.

Јов Н. (1999), Der Wandel der historischen Kulturlandschaft und sein Stellenwert in der Raumordnung (= Forschungen z. dt. Landeskunde, 248). Flensburg, Dt. Akad. f. Landeskunde, Selbstverlag.

Јов Н. (2005), Die Alpen als Destination - eine Analyse in vier Dimensionen. In: Mitt. d. Österr. Geogr. Ges., 147, S. 113-138. 
JÜLG F. (2001), Österreich - Zentrum und Peripherie im Herzen Europas. Gotha, Klett Perthes.

KAPELLER K. (1991), Tourismus und Volkskultur: Folklorismus - zur Warenästhetik der Volkskultur. Graz, dbv-Verlag.

Kariel H.G., Kariel P.E. (1982), Socio-Cultural Impacts of Tourism: An Example from the Austrian Alps. In: Geografiska Annaler B, 64, 1, S. 1-16.

Kariel H.G. (1989), Socio-Cultural Impacts of Tourism in the Austrian Alps. In: Mountain Research and Development, 9, 1, S. 59-70.

KELLER W. (2007), Siedlungstypen und Siedlungsentwicklung in Tirol. Anmerkungen zu einer nicht erschienenen Karte im Analogen Tirol-Atlas. In: Innsbrucker Geographische Gesellschaft (Hrsg.), Alpine Kulturlandschaft im Wandel, S. 51-65. Innsbruck.

Kessler H. (1990), Berglandwirtschaft und Ferienhaustourismus. Wenn der Kuhstall zum Ferienhaus und das Mistseil zum Skilift wird ... - Fallstudien zum Kulturlandschaftswandel in Berggebieten mit landwirtschaftlich-touristischer Mischnutzung in den Kantonen Nidwalden, Glarus und Graubünden (= Basler Beiträge z. Geogr., 36). Basel, Wepf \& Co.

Kianicka S., Knab L., Buchecker M. (2010), Maiensäss - Swiss Alpine summer farms - an element of cultural heritage between conservation and further development: a qualitative case study. In: Int. Journal of Heritage Studies, 16, 6, S. 86-107.

Kitzbüheler Alpen Marketing GmbH, Kuenstleragentur Koenig, Agentur TexTour (Hrsg.) (2008), Hansi Hinterseer - Fanwanderung. - http://www.kitzalps.com/images/bilder/ kitzbueheler-alpen_hansi-hinterseer-fanwanderung-1_kitzbuehel-tourismus-cby-kuenst leragentur-koenig-und-agentur-textour.jpg (Abrufdatum 10.07.2011)

KIRCHENGaST C. (2008), Über Almen zwischen Agrikultur und Trashkultur (= alpine space - man \& environment, 5). Innsbruck, Innsbruck Univ. Press.

Knafou R. (1978), Les stations intégrées de sports d'hiver des Alpes françaises. Paris, Persee.

KonoLD W. (2007), Dynamik und Wandel von Kulturlandschaften. Was können Biosphärenreservate leisten? In: UNESCO heute. Zeitschrift d. Dt. UNESCO-Kommission, 54, 2, S. 19-22.

KRIPPENDORF J. (1975), Die Landschaftsfresser, Tourismus und Erholungslandschaft - Verderben oder Segen? Bern, Hallwag.

KrIPPENDORF J. (1987²), Alpsegen. Alptraum. Für eine Tourismus-Entwicklung im Einklang mit Mensch und Natur. Bern, Kümmerly \& Frey.

Leitner W. (1984), Winterfremdenverkehr - Entwicklung, Erfahrungen, Kritik, Anregungen. Bundesland Salzburg 1955/56-1980/81 (= Salzburg Information, Sonderpubl., 54). Salzburg.

Lichtenberger E. (1979), Die Sukzession von der Agrar- zur Freizeitgesellschaft in den Hochgebirgen Europas. In: Institut für Geographie DER Universität InNSBRUCK (Hrsg.), Fragen geographischer Forschung. Festschrift des Instituts für Geographie zum 60. Geburtstag von Adolf Leidlmair (= Innsbrucker Geogr. Studien, 5), S. 401-436. Innsbruck, Inst. f. Geogr. d. Univ. Innsbruck.

Lieberherr-Gardiol F. (1984), Des hommes et des natures. Le Pays-d'Enhaut en 1984, Synthese partielle, Tome $1+2$ (= Schlussberichte z. schweizer. MAB-Programm, 8/1 u. 8/2). Bern, Bundesamt f. Umweltschutz.

LiNGG A. (1998), Investitionen nach innen. Lebensgestaltung, Familie und Tourismus. Strategien zur Minderung tourismusbedingter Belastungen. In: IsENBERG W. (Hrsg.), Tourismus Gewinn oder Verlust von Identität? Die Wechselwirkungen von Kultur und Tourismus (= Bensberger Protokolle, 88. Schriftenreihe d. Thomas-Morus-Akad. Bensberg), S. 57-60. Bergisch-Gladbach, Thomas-Morus-Akad. Bensberg.

Lorenz P. (1998), Freizeitarchitektur - Baukunst oder Kitsch? In: IsenBerg W. (Hrsg.), Tourismus - Gewinn oder Verlust von Identität? Die Wechselwirkungen von Kultur und Tourismus (= Bensberger Protokolle, 88, Schriftenreihe d. Thomas-Morus-Akad. Bensberg), S. 45-55. Bergisch-Gladbach, Thomas-Morus-Akad. Bensberg. 
LöHR L. (1971), Bergbauernwirtschaft im Alpenraum. Ein Beitrag zum Agrarproblem der Hangund Berggebiete. Graz, Stocker-Verlag.

LÜEM T. (1985), Soziokulturelle Auswirkungen des Tourismus in Entwicklungsländern. Ein Beitrag zur Problematik des Vergleiches von touristischen Implikationen auf verschiedenartige Kulturräume der Dritten Welt (= Anthropogeogr. d. Univ. Zürich, 5). Zürich, Zentralstelle d. Studentenschaft.

LugER K. (1995), Kulturen im Veränderungsstreß. Kulturtheoretische Überlegungen zur Tourismusdebatte. In: Luger K., Inmann K. (Hrsg.), Verreiste Berge - Kultur und Tourismus im Hochgebirge, S. 19-42, Innsbruck, Studien-Verlag.

Luger K. (1998), Die Alpenjugend im Modernisierungsstress. In: Bachleitner R., Kagelmann H.J., Keul A.G. (Hrsg.), Der durchschaute Tourist. Arbeiten zur Tourismusforschung (= Tourismuswiss. Manuskripte, 3), S. 49-61, München, Profil Verlag.

Luger K., Rest F. (2002), Der Alpentourismus. Konturen einer kulturell konstruierten Sehnsuchtslandschaft. In: Luger K., Rest F. (Hrsg.), Der Alpentourismus - Entwicklungspotenziale im Spannungsfeld von Kultur, Ökonomie und Ökologie, S. 11-46. Innsbruck, Studien-Verlag.

MacCannell D. (1973), Staged authenticity: Arrangements of social space in tourist settings. In: The American Journal of Sociology, 79, 3, S. 589-603.

MacCannell D. (1976), The tourist: a new theory of the leisure class. New York, Univ. of California Press, Ltd.

Maletzke G. (1996), Interkulturelle Kommunikation. Zur Interaktion zwischen Menschen verschiedener Kulturen. Opladen, Westdt. Verlag.

Mannhart A.E. (1986), Landwirtschaft und Tourismus: Konkurrenz oder Ergänzung? Regionalstudie Sarganserland-Walensee, Zürich, Zentralstelle d. Studentenschaft.

Mansperger M. (1995), Tourism and Cultural Change in Small-Scale Societies. In: Human Organization, 54, 1, S. 87-94.

MAYER M. (2009), Innovation as a success factor in tourism: empirical evidence from western Austrian cable-car companies. In: Erdkunde, 63, 2, S. 123-139.

Mayer M., Steiger R., Trawöger L. (2007), Technischer Schnee rieselt vom touristischen Machbarkeitshimmel - Schneesicherheit und technische Beschneiung in westösterreichischen Skidestinationen vor dem Hintergrund klimatischer Wandlungsprozesse. In: Mitt. d. Österr. Geogr. Ges., 149, S. 157-180.

Mayer M., Woltering M., Jов H. (2008), Tourismus und Regionalentwicklung in den bayerischen Alpen. In: Geogr. Rundschau, 60, 10, S. 40-46.

MaYer M., Joв H. (2010), Raumrelevante Konflikte zwischen Almwirtschaft, Naturschutz und Tourismus. Ergebnisse einer Befragung in den oberbayerischen Alpen. In: Naturschutz u. Landschaftsplanung, 42, 2, S. 55-63.

MaYer M., Joв H., Ruppert K. (2010), Raumfunktionale Zusammenhänge zwischen Almwirtschaft und Tourismus in den Nördlichen Kalkalpen: Fallbeispiele Isarwinkel (Bayern) und Rissbach-/Bächental (Tirol). In: Berichte z. dt. Landeskunde, 84, 1, S. 59-88.

Mayrock G. (1996), Alpwirtschaft und Tourismus bei unseren Allgäuer Nachbarn. In: Der Almbauer, 10, S. 107-108.

Meleghy T., Preglau M., Tafertshofer A. (1985), Tourism development and value change. In: Annals of Tourism Research, 12, S. 181-199.

Meleghy T., Preglau M., Tafertshofer A. (1987), Touristische Entwicklung, Strukturwandel und Wandel von Wertvorstellungen. In: Patzelt G. (Schriftleitung), MaB-Projekt Obergurgl (= Veröff. d. Österr. MaB-Programms, 10), S. 115-132. Innsbruck, Univ.-verlag Wagner.

Meleghy T., Preglau M. (1988), Touristische Erschliessung und soziokulturelle Entwicklung - am Beispiel Obergurgl. In: Elsasser H., Reith W.J., Schmid W.A. (Hrsg.), Kulturelle Vielfalt, regionale und örtliche Identität - eine sozio-kulturelle Dimension in der Raum- 
planung?, S. 151-178. Wien, Eigenverlag d. Inst. f. Raumplanung u. Agrar. Operationen, Univ. f. Bodenkultur Wien.

Messerli P. (1987), The Development of Tourism in the Swiss Alps: Economic, Social, and Environmental Effects. Experience and Recommendations from the Swiss MAB Programme. In: Mountain Research and Development, 7, 1, S. 13-23.

Messerli P. (1989), Mensch und Natur im alpinen Lebensraum - Risiken, Chancen, Perspektiven. Bern, Haupt.

Meyrat-Schlee E. (1982), Soziokulturelle Aspekte der Entwicklung der Gemeinde Grindelwald. In: Krippendorf J., Messerli P., Hänni H. (Hrsg.), Tourismus und regionale Entwicklung, S. 191-196. Diessenhofen, Rüegger.

Meyrat-Schlee E. (1983), Werte und Verhalten - Bedeutung und Wirkungsweise von Wertesystemen im Entwicklungsprozess einer Berggemeinde, aufgestellt am Beispiel Grindelwald (= Schlussberichte z. Schweizer. MAB-Programm, 2). Bern.

Moser P., Moser W. (1986), Reflections on the MAB-6 Obergurgl Project and Tourism in an Alpine Environment. In: Mountain Research and Development, 6, 2, S. 101-118.

Mörth I. (1997), Auf die Dosis kommt es an. Tourismus als Dünger regionaler Kultur? In: Tourismus Journal, 1, 3-4, S. 483-490.

MöRTH I. (2004), Fremdheit, wohldosiert. Tourismus als Kultur der kontrollierten Begegnung mit dem Fremden. In: TRANS, Internet-Zeitschrift f. Kulturwiss., 15/2003 . - http:// www.inst.at/trans/15Nr/09_1/moerth15.htm (Abrufdatum 27.05.2011)

Müller H. (1986), Tourismus in Berggemeinden: Nutzen und Schaden. Eine Synthese der MaB-Forschungsarbeiten aus tourismuspolitischer Sicht (= Schlussberichte z. Schweizer. MaB-Programm, 19). Bern, Bundesamt f. Umweltschutz.

MüLler H. (2001), Die ortsansässige Bevölkerung und ihr Tourismusbewusstsein. In: Voyage - Jahrbuch f. Reise- \& Tourismusforschung, 4, S. 125-136.

Mundt J.W. (2011), Tourism and Sustainable Development. Reconsidering a Concept of Vague Policies. Berlin, Erich Schmidt.

Niederer A. (1996²), Die alpine Alltagskultur zwischen Routine und der Adoption von Neuerungen. In: Anderegg K., Bätzing W. (Hrsg.), Arnold Niederer. Alpine Alltagskultur zwischen Beharrung und Wandel. Ausgewählte Arbeiten aus den Jahren 1956 bis 1991 S. 116-138. Bern, Haupt.

ÖFner J. (1994), Gurgler Gemat. In: HaId G., HaId H. (Hrsg.), Brauchtum in den Alpen. Riten, Traditionen, lebendige Kultur, S. 197-206. Bad Sauerbrunn, Rosenheimer Verlag.

Penz H. (1978), Die Almwirtschaft in Österreich (= Münchner Studien z. Sozial- u. Wirtschaftsgeogr., 15). Kallmünz/Regensburg, Lassleben.

Pevetz W. (1983), Fremdenverkehr und Landwirtschaft in Österreich. In: Berichte über Landwirtschaft, 61, S. 280-301.

Pevetz W. (1998), Die Multifunktionalität der österreichischen Land- und Forstwirtschaft (= BA f. Agrarwirtschaft Schriftenreihe, 82). Wien, BA f. Agrarwirtschaft.

PhILIPP W. (1974), Seilbahnen und Lifte im Bayerischen Alpenraum (= WGI-Berichte z. Regionalforschung, 2). München, Geo-Buch Verlag.

Pingold M. (2007), Wahrnehmung und Bewertung des Landschaftswandels in Bad Hindelang im Allgäu - eine Untersuchung der Sichtweisen von Experten, Einheimischen und Touristen. Duisburg, Wiku-Wissenschaftsverlag.

Preglau M. et al. (1985), Fremdenverquer. Kosten und Nutzen des Tourismus am Beispiel Obergurgl (= Schriftenreihe d. Michael-Gaismair-Ges., 4). Innsbruck, Michael-Gaismair-Ges.

Preglau M. (1998), Kolonialisierung der Lebenswelt? Zum heuristischen Potential und zur empirischen Bewährung eines Theorems in der „Bereisten“-Forschung. In: B ACHLEITNER R., Kagelmann H.J., Keul A.G. (Hrsg.), Der durchschaute Tourist. Arbeiten zur Tourismusforschung (= Tourismuswiss. Manuskripte, 3), S. 49-61. München, Profil Verlag. 
Pröвstl U. (2006), Kunstschnee und Umwelt: Entwicklung und Auswirkungen der technischen Beschneiung. Bern, Haupt.

RAdEMACHER A. (2006), Landschaftsschäden durch Sommer- und Wintertourismus im Freizeitraum Allgäuer Alpen einschließlich des Kleinwalsertals. Marburg, Tectum-Verlag.

Redfield R., Linton R., Herskovits M. (1936), Memorandum for the Study of Acculturation. In: American Anthropologist, 38, 1, S. 149-152.

ReID D.G. (2003), Tourism, Globalization and Development. Responsible Tourism Planning. London, Pluto Press.

Ressi W. et al. (2006), Programm und Plan zur Entwicklung der Almwirtschaft (= ALP Austria Programm z. Sicherung u. Entwicklung d. alpinen Kulturlandschaft). Wien. - http://www. almwirtschaft/com/images/stories/fotos/alpaustria/pdf/RessiGlatzEggerBogner_Programm Plan.pdf (Abrufdatum 14.01.2008).

REst F. (1995), Kulturelle Identität und transkulturelle Heimat. Tourismus als Bewahrer und Bedroher kultureller Identität. In: LugER K., InMAnN K. (Hrsg.), Verreiste Berge - Kultur und Tourismus im Hochgebirge, S. 81-94. Innsbruck, Studien-Verlag.

Ringler A. (2009), Almen und Alpen. Höhenkulturlandschaft der Alpen - Ökologie, Nutzung, Perspektiven. München, Verein z. Schutz d. Bergwelt.

Rixen C., Stoeckli V., Ammann W. (2003), Does artificial snow production affect soil and vegetation of ski pistes? A review. In: Perspectives in Plant Ecology Evolution and Systematics, 5, S. 219-230.

Rohrer J., Rösch P. (2002), Alpine Erinnerungswelten. In: Luger K., Rest F. (Hrsg.), Der Alpentourismus - Entwicklungspotenziale im Spannungsfeld von Kultur, Ökonomie und Ökologie, S. 105-125. Innsbruck, Studien-Verlag.

Runte A. (1977), The National Park Idea: Origins and Paradox of the American Experience. In: Journal of Forest History, 21, 2, S. 64-75.

RUPPERT K. (1963), Almwirtschaft und Fremdenverkehr in den Bayerischen Alpen. Ein Beitrag zum kulturgeographischen Entwicklungsproblem im Hochgebirge. In: Deutscher Geographentag Heidelberg 4. bis 7. Juni 1963. Tagungsbericht u. wiss. Abhandlungen. Verhandlungen d. Dt. Geographentags, 34, S. 325-331.

RUPPERT K. (1976), Kulturlandschaft erhalten heißt Kulturlandschaft gestalten. In: MAYER-TASCH P.C. (Hrsg.), Kulturlandschaft in Gefahr, S. 37-46. München, Bayer. Landeszentrale f. Polit. Bildungsarbeit.

Sauter J. (1993), Alkoholkonsum und Tourismus. In: Hahn H., Kagelmann H.J. (Hrsg.), Tourismuspsychologie und Tourismussoziologie: ein Handbuch zur Tourismuswissenschaft, S. 239-244. München, Quintessenz-Verlag.

SCHAER U. (1982), Der Tourismus im Berggebiet. In: DISP, 65, S. 31-35.

SCHENK W. (2001), Kulturlandschaft in Zeiten verschärfter Nutzungskonkurrenz: Genese, Akteure, Szenarien. In: ARL (Hrsg.), Die Zukunft der Kulturlandschaft zwischen Verlust, Bewahrung und Gestaltung (= Forschungs- u. Sitzungsberichte ARL, 215), S. 30-44. Hannover, ARL.

Schimany P. (1997), Tourismus und Kultur. Zusammenhänge und Prozesse in vergleichender Perspektive. In: Tourismus Journal, 1, 2, S. 167-192.

Siegrist D. (1998), Daten zu Tourismus und Freizeit. In: CIPRA (Hrsg.), 1. Alpenreport. Daten Fakten Probleme Lösungsansätze, S. 418-441. Bern, Haupt.

Sмiтн V. (1977), Introduction. In: Sмiтн V. (Hrsg.), Hosts and Guests. The Anthropology of Tourism, S. 1-14. Oxford, Univ. of Pennsylvania Press.

Socher K., Tschurtschenthaler P. (1994), Tourism and agriculture in alpine regions. In: The Tourist Review, 3, S. 35-41.

Stattmann E. (1981), Entwicklung, Struktur sowie derzeitige Situation des Personals auf oberbayerischen Almen - dargestellt am Beispiel der Landkreise Bad Tölz-Wolfratshausen, Miesbach und Rosenheim. In: Bayer. Landwirtschaftl. Jahrbuch, 58, S. 532-590. 
Steiger R., Mayer M. (2008), Snowmaking and Climate Change: Future possibilities for snow production in Tyrolean ski resorts. In: Mountain Research and Development 28, 3-4, S. 292-298.

TAppeiner U., Borsdorf A., TAsser E. (Hrsg.) (2008), Alpenatlas. Society - Economy - Environment. Heidelberg, Springer.

Thiem M. (1994), Tourismus und kulturelle Identität. Die Bedeutung des Tourismus für die Kultur touristischer Ziel- und Quellgebiete (= Berner Studien z. Freizeit u. Tourismus, 30), Bern, Forschungsinst. f. Freizeit u. Tourismus d. Univ. Bern.

Thiем M. (2001), Tourismus und kulturelle Identität. In: Aus Politik u. Zeitgeschichte, B47, S. 27-31. - http://www.bpb.delfiles/JOIKZM.pfd (Abrufdatum 28.05.2011)

TERKENLI T. $\left(2000^{2}\right)$, Landscapes of tourism: a cultural geographical perspective. In: BRIASSOULIS H., van der StraAten J. (Hrsg.), Tourism and the environment. Regional, economic, cultural and policy issues, S. 179-202. Dordrecht, Kluwer.

Terkenli T.S. (2004), Tourism and Landscape. In: Lew A.A., Hall C.M., Williams A.M. (Hrsg.), A Companion to Tourism, S. 339-348. Malden, Wiley.

Tomasi E. (1978), Sozio-ökonomische Veränderungen im bäuerlichen Betrieb und Haushalt durch den Fremdenverkehr - am Beispiel dreier Gemeinden im Oberpinzgau (Salzburg). In: Geogr. Jahresbericht aus Österr., 36, S. 50-79.

Tschurtschenthaler P. (1986), Das Landschaftsproblem im Fremdenverkehr dargestellt anhand der Situation des Alpenraums. Eine ökonomische Analyse. Bern, Haupt.

UNESCO (Hrsg.) (1976), The effects of tourism on socio-cultural values. In: Annals of Tourism Research, 4, 2, S. 74-104.

Wechselberger F. (2004), Die Seilbahnen im Zillertal - Eine Grundsäule des Tourismus. Unveröff. Manus., Zell a. Ziller.

Wilhelm U. (1977), Die soziale Beziehung zwischen Gastgebern und Gästen. Aufgezeigt am Beispiel zweier Fremdenverkehrszentren im Ötztal. Diss., Univ. Innsbruck.

WiLhelm U. (2001), Auf dem Weg zum professionellen Umgang mit dem Gast. Zwei sozialpsychologische Untersuchungen über das Verhältnis von Gastgebern und Gästen im Ötztal 1976 und 1997. In: Voyage - Jahrbuch f. Reise- \& Tourismusforschung, 4, S. 137-154.

Zimmermann F. (1995), The Alpine Region: Regional Restructuring Opportunities and Constraints in a Fragile Environment. In: Montanari A., Williams A.M. (Hrsg.), European Tourism: Regions, Spaces, and Restructuring, S. 19-40. New York, Wiley.

ZEIT Magazin (Hrsg.) (2010), Hüttenzauber. Die Après-Ski Industrie Österreichs - vor und hinter der Theke. In: ZEIT Magazin, 6, S. 18-25.

ZuZAn W.D. (1975), Das Verhältnis Gast - Gastgeber in einem ausgewählten Reisegebiet. In: Schmitz-Scherzer R. (Hrsg.), Reisen und Tourismus (= Praxis d. Sozialpsychologie, 4), S. 99-108. Darmstadt, Steinkopff.

\section{Appendix: Quellen von Abb. 1}

Eigene Darstellung nach BLfStaD 2011, Statistical Office of the Republic of Slovenia 2011, WKNOE 2011, Statistik Austria 2010, Amt der KärntNer LANDESREgierung 2010a,b; Amt der Steiermärkischen Landesregierung 2011a,b; Land SAlzburg 2010a,b; Amt Der VorARLBerger Landesregierung 2010a,b; Amt Der Tiroler LandesRegierung 2011; ASTAT 2011; Provincia Autonoma di Trento 2011, Regione del Veneto 2011, Regione Lombardia 2006, Regione Piemonte 2011, Regione Lombardia 2011, Regione Piemonte 2011, INSEE 2011, BFS 2011, BFS 2004, BFS 2003a-e, LUSTAT 2011, Fachstelle für Statistik Kanton St. Gallen 2011, Repubblica e Cantone Ticino 2010, Amt für Wirtschaft und Tourismus Graubünden 2011, Amt Für Statistik des Kantons Freiburg 2009, Tappeiner et al. 2008, 74ff. 
Amt der Kärntner Landesregierung (Hrsg.) (2010a), Tourismusstatistik. Sommersaison 2009/ 2010. - http://www.statistik.ktn.gv.at/205425_DE_FRVGemeinden-SH10

Amt der KÄrntner LANDESREgierung (Hrsg.) (2010b), Tourismusstatistik. Wintersaison 2009/2010. - http://www.statistik.ktn.gv.at/190701_DE_FRVGemeinden-WHJ10

Amt der Steiermärkischen LAndesregierung (Hrsg.) (2011a), Tourismus. Analysen Sommerhalbjahr 2010. - http://www.verwaltung.steiermark.at/cms/beitrag/11380734/35581380

Amt DER SteIERMÄrkischen LANDESREgIERUng (Hrsg.) (2011b), Tourismus. Analysen Winterhalbjahr 2009/2010. - http://www.verwaltung.steiermark.at/cms/beitrag/11283713/35581380

Amt Der Tiroler Landesregierung (2011) (Hrsg.), Tourismus in Tirol. - http://www.tirol.gv.at/ themen/zahlen-und-fakten/statistik/tourismus/\#c76985 (Stand: 2009/2010)

Amt der Vorarlberger Landesregierung (2010a) (Hrsg.), Tourismus - Sommer 2010 - - http:// www.vorarlberg.at/pdf/tourismussommer2010vorlae.pdf

Amt der Vorarlberger Landesregierung (2010b) (Hrsg.), Tourismus - Winter 2009/2010 . http://www.vorarlberg.at/pdf/tourismuswinter2009_2010v.pdf

Amt Für Statistik des Kantons Freiburg (Hrsg.) (2009), Statistisches Jahrbuch des Kantons Freiburg 2010. Fribourg. - http://www.fr.ch/sstat/files/pdf21/annuaire-statistique-fr-2010.pdf

Amt FÜR Wirtschaft und Tourismus Graubünden (Hrsg.) (2011), Parahotellerie Logiernächte nach Gemeinden 1992-2003 Fremdenverkehrsjahr. - http://www.gr.ch/DE/institutionen/ verwaltung/dvs/awt/dokumentation/Dokumente\%20Volkswirtschaftliche\%20Grundlagen/ Parahotellerie_Logiern\%C3\%A4chte\%20nach\%20Gemeinden_1992_2003_Fremdenver kehrsjahr.xls

Autonome Provinz Bozen-Südtirol - Landesinstitut für Statistik (ASTAT) (Hrsg.) (2011), Tourismus in Südtirol. Tourismusjahr 2009/10. Bozen. - http://www.provinz.bz.it/astat/ de/mobilitaet-tourismus/471.asp?Tourismus_action=4\&Tourismus_article_id=167595

Bayerisches Landesamt für Statistik und Datenverarbeitung (BLfStaD) (Hrsg.) (2011), Übernachtungsstatistik GENESIS-Online. - https://www.statistikdaten.bayer.de/genesis/ online/logon (Stand: 2009/10)

Bundesamt für Statistik (BFS) (Hrsg.) (2003a), Tourismus im Kanton Bern. Hotellerie und Parahotellerie. Fremdenverkehrsjahr 2001/2002. Neuchâtel. - http://www.bfs.admin.ch/ bfs/portal/de/index/themen/10/22/publ.Document.26003.pdf

Bundesamt Für Statistik (BFS) (Hrsg.) (2003b), Tourismus im Kanton Graubünden. Hotellerie und Parahotellerie. Fremdenverkehrsjahr 2000/2001. Neuchâtel. - http://www.bfs.admin. ch/bfs/portal/de/index/themen/10/22/publ.Document.25990.pdf

Bundesamt für Statistik (BFS) (Hrsg.) (2003c), Tourismus im Kanton Obwalden. Hotellerie und Parahotellerie. Fremdenverkehrsjahr 2001/2002. Neuchâtel. - http://www.bfs.admin . ch/bfs/portal/de/index/themen/10/22/publ.Document.25986.pdf

Bundesamt FÜR Statistik (BFS) (Hrsg.) (2003d), Tourismus im Kanton Tessin. Hotellerie und Parahotellerie. Fremdenverkehrsjahr 2001/2002. Neuchâtel. - http://www.bfs.admin.ch/ bfs/portal/de/index/themen/10/22/publ.Document.26009.pdf

Bundesamt FÜR Statistik (BFS) (Hrsg.) (2003e), Tourismus im Kanton Wallis. Hotellerie und Parahotellerie. Fremdenverkehrsjahr 2001/2002. Neuchâtel. - http://www.bfs.admin.ch/ bfs/portal/de/index/themen/10/22/publ.Document.26007.pdf

Bundesamt für Statistik (BFS) (Hrsg.) (2004), Parahotelleriestatistik: Anzahl Betriebe und Schlafplätze nach Gemeinden. Fremdenverkehrsjahr 2003 (November 2002 - Oktober 2003). Neuchâtel.

BundeSAMt FÜR STATISTIK (BFS) (Hrsg.) (2011), Hotellerie: Angebot und Nachfrage der geöffneten Betriebe nach Gemeinde. Logiernächte 2010. - http://www.bfs.admin.ch/bfs/portal/de/ index/themen/10/03/blank/key/01/04.Document.64547.xls 
Fachstelle für Statistik Kanton St. Gallen (Hrsg.) (2011), Aufenthaltstourismus. - http:// www.statistik.sg.ch/home/themen/b10/aufenthalt.html (Stand: 2009/10)

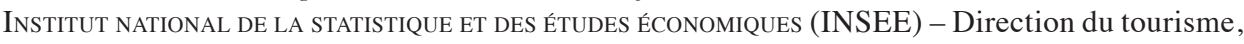
hébergements touristiques (Hrsg.) (2011), Hébergements touristiques des communes, 2007, 2008 et 2011. - http://www.insee.fr/fr/ppp/bases-de-donnees/donnees-detaillees/ base-cc-tourisme/base-cc-tourisme-MET-11.zip

Land Salzburg (Hrsg.) (2010a), Der Tourismus im Land Salzburg. Übernachtungen Winter 2009/2010. - http://www.salzburg.gv.at/winter_2009_2010-2.pdf

Land Salzburg (Hrsg.) (2010b), Der Tourismus im Land Salzburg. Übernachtungen Sommer 2010. - http://www.salzburg.gv.at/sommer_2010-2.pdf

Provincia Autonoma di Trento - Servizio statistica (Hrsg.) (2011), Presenze stagionali ed annuali per comprensorio e commune. - http://www.statweb.provincia.tn.it/Pubblicazi oni/Tur/AnnTur2009/Capitolo2/T02_056.html (Stand: 2009)

Regione Autonoma Friuli Venezia Giulia (Hrsg.) (2011), Presenze per stagione 2010. Freundl. schriftl. Mitt. d. Statistischen Amts vom 10.06.2011.

Regione Autonoma Valle D'Aosta (Hrsg.) (2011), Übernachtungen auf Gemeindeebene 2010/2011. Freundl. schriftl. Mitt. d. Statist. Amts vom 10.06.2011 (Stand: 2010/11).

Regione del Veneto (Hrsg.) (2011), Movimento turistico nel Veneto. Dati a livello comunale. Anno 2010. Alcuni fra i principali comuni turistici. - http://statistica.regione.veneto. it/turismo4.jsp

Regione Lombardia - Statistica e Osservatori (Hrsg.) (2006), Flussi turistici per provenienza - anno 2005 - comuni. - http://www.statistica.regione.lombardia.it/EseguiBBS. asp? Visualizza $=$ SI (Stand: 2005)

Regione Piemonte Direzione Turismo (Hrsg.) (2011), Anno 2010. Dati turistici suddivisi per comune. Movimenti nei comuni. - http://www.regione.piemonte.it/turismo/osservatorio/ $d w d / 2010 /$ Scheda\%20C2\%20-\%20pagg\%2052\%20COMUNI\%20-\%20MOVIMENTI\%20 2010.pdf

Repubblica e Cantone Ticino - Ufficio di statistica (Hrsg.) (2010), Offerta turistica, domanda turistica e tassi di occupazione nel settore alberghiero, nel 2009 (stabilimenti aperti). http://www.ti.ch/DFE/USTAT/DATI_RIEPILOGHI/default_x_asp? menu=10\&key1_testo $=$ Turismo\&key $1=10 \&$ key $2=03 \&$ key $3=01$

StATISTIK Austria (Hrsg.) (2010), Tourismus in Österreich. Ergebnisse der Beherbergungsstatistik 2009. Wien. - http://www.statistik.at/dynamic/wcmsprod/idcplg? IdcService=GET_NATIVE_FILE\&dID $=70694 \& d$ DocName $=045278$

STATISTIK LUZERN (LUSTAT) (Hrsg.) (2011), Hotellerie: Angebot und Nachfrage 2010. Gemeinden Kanton Luzern. - http://www.lustat.ch/download/lustat_new/kt/0003/w103_001t_ kt0003_gd_d-2010_097.html

Statistical Office of the Republic of Slovenia (Hrsg.) (2011), Accommodation facilities, tourist arrivals and overnight stays, municipalities, Slovenia, monthly. - http://pxweb.stat.si/ pxweb/Dialog/varval.asp? $\mathrm{ma}=2164404 E \& t i=\&$ path $=. . /$ Database $/$ Economy $/ 21 \_$hotels tourism/01_21644_accomod_month/\&lang=1 (Stand: 2010)

Tappeiner U., Borsdorf A., Tasser E. (Hrsg.) (2008), Alpenatlas. Society - Economy - Environment. Heidelberg, Springer.

WirTSCHAFTSKAMMER NiedERÖSTERREICH (Hrsg.) (2011), Tourismusstatistik 2010. - http://www. wko.at/wknoe/stat/tourismus\%201998/TOURISMUSSTATISTIK\%202010.pdf

Abrufdatum der Online-Seiten zwischen März und Juni 2011 